\title{
Constitución de servidumbres sobre predio propio por acto jurídico unilateral del dueño: destinación formal del padre de familia y relectura del "servicio aparente""
}

\section{Gian franco Rosso Elorriaga*}

Resumen. En virtud del principio nemini res sua servit iure servitutis, tradicionalmente se le ha negado al propietario la constitución de servidumbres mediante acto jurídico unilateral entre predios propios. Esta imposibilidad ha derivado en una limitación perjudicial para los intereses patrimoniales de los dueños. Algunas legislaciones han introducido excepciones al principio, dando vida a las denominadas "servidumbres de propietario". Para permitir a los dueños la constitución de servidumbres sin cumplir con el requisito de la ajenidad, los doctrinarios han reinterpretado las normas vigentes. En esta línea, se efectúa una relectura de la expresión "servicio aparente" de los artículos 88 I c.c. chil. y 938 c.c. col., comprendiendo en ella la destinación formal del propietario, solucionando el problema a través de la "destinación del padre de familia".

Fecha de recepción: I de julio de 20I6. Fecha de aceptación: 3 I de octubre de 2016.

Para citar el artículo: G. F. Rosso Elorriaga, "Constitución de servidumbres sobre predio propio por acto jurídico unilateral del dueño: destinación formal del padre de familia y relectura del 'servicio aparente", Revista de Derecho Privado, Universidad Externado de Colombia, n. ${ }^{\circ} 3$ I, julio-diciembre de 20I6, I I I-I 49. Dor: http://dx.doi.org/IO.I 860I/OI 234366.n31.05

La redacción de este artículo ha contado con la ayuda del Fondo Nacional de Ciencia y Tecnología de la República de Chile, en el marco del Proyecto Fondecyt Iniciación n. ${ }^{\circ}$ I I 140856 , titulado "El régimen jurídico de las servidumbres voluntarias: propuesta de reformulación dogmática a la luz de la funcionalidad actual de las disposiciones del código civil y de la legislación especial", en el cual el autor es investigador responsable.

** Doctor en Derecho y Magíster por la Università degli Studi di Roma 'Tor Vergata', Roma, Italia. Profesor de Derecho Civil y Derecho Romano en la Facultad de Derecho de la Universidad de los Andes, Santiago de Chile, Chile. Contacto: grosso@uandes.cl 
Palabras clave: constitución de servidumbres, nemini res sua servit, servidumbre de propietario, servicio aparente, destinación del padre de familia.

\section{Constitution of Servitudes on Own Property by Unilateral Imposition of the Owner: Formal Destination of the Family Father and Reinterpretation of the "Apparent Charge"}

Aвstract: According to the principle nemini res sua servit iure servitutis, the owner is traditionally not allowed to unilaterally impose a servitude between own property. This impossibility has led to a harmful limitation to the pecuniary interests of the owner. Some legislations have introduced exceptions to that principle, thereby creating the "servitudes of the owner". To allow the owners to constitute servitudes without meeting the requirement that dominant and servant lands must belong to different owners, doctrinaires have reinterpreted the current norm. Therefore, a rereading of the "apparent charge" of articles $88 \mathrm{I}$ and 938 of the Chilean and Colombian Civil Codes, respectively is done, which entails the formal destination of the owner, solving the problem through "destination made by the family father".

Keywords: Constitution of servitudes, nemini res sua servit, servitude of the owner, apparent charge, destination made by the father.

Sumario: i. El principio nemini res sua servit iure servitutis. II. Las excepciones modernas al principio nemini res sua servit iure servitutis. III. La destinación del padre de familia (DPF): el "servicio aparente". Iv. El principio nemini res sua servit iure servitutis en beneficio del propietario y la reconducción del establecimiento formal de servicios efectuado por el propietario hacia la destinación del padre de familia. v. Argumentos complementarios en favor de la reconducción propuesta. Conclusiones.

\section{El principio nemini res sua servit iure servitutis}

Entre los principios fundantes de la reglamentación civil de las servidumbres se encuentra aquel sintetizado en el brocardo nemini res sua servit: la cosa propia no sirve a nadie (al propietario). Su sentido, aplicado a la materia que tratamos, sería que no puede constituirse una servidumbre entre predios que pertenecen al mismo dueño (un predio propio no puede "servir", subordinarse o someterse, mediante servidumbre, a otro predio propio). 
Se trata de un principio de origen romano del cual darían cuenta varios pasajes de las fuentes justinianeas ${ }^{\mathrm{I}}$. Los textos supérstites presentan sin embargo diversos problemas de fondo y forma, adquiriendo los mismos un carácter controvertido en la romanística ${ }^{2}$. Entre las dificultades tradicionales se encuentra la circunstancia de que el servire al que originalmente pudieron haberse referido los jurisprudentes debió corresponder a la sujeción jurídica de un predio a otro mediante una "servidumbre predial"; es decir, inicialmente el término tenía un sentido restringido 3 . Su evolución del derecho clásico romano al derecho bizantino comportó un ensanchamiento tal de su parte que significó correlativamente una ampliación del concepto de servidumbre. Así, en las fuentes aludidas se distinguen las categorías de las servitutes praediorum (servidumbres prediales) y de las servitutes personarum (derechos reales de usufructo, uso o habitación)4 4 . De ahí que el principio nemini res sua servit históricamente resulte aplicado no sólo a las servidumbres sino también a todos los derechos reales limitados ${ }^{5}$.

Este resultado tiene por base, en definitiva, una subjetivación de la regla aludida, pues ya no se trata de que un fundo no pueda servir a otro fundo del mismo dueño, sino de que una cosa propia no puede servir "a su propietario" a través

I Principalmente en D. 8.2.26 (nulli enim res sua servit), D. 8.4.I (nemo ipse sibi servitutem debet), D. 8.3.33.I (nullum praedium ipsum sibi servire) y D. 8.3.3 I (ipsa sibi servire non potuissent), todos en materia de servidumbres prediales. Asimismo en D. 7.6 .5 pr. (nec enim potest ei suus fundus servire), en materia de usufructo.

2 En general, no son consideradas genuinas las supuestas referencias al principio en D. 8.2.26, D. 7.6.5 pr. y D. 8.4.Io. En cambio, clásicos sí serían D. 8.3.33.I y D. 8.3.3 I. Entre otros, Longo, C., "La categoria delle "servitutes" nel diritto romano classico", Bullettino dell'Istituto di Diritto Romano 'Vittorio Scialoja', Roma, I I, I898, 3 I 3 y 3 I4; Solazzi, S., Requisiti e modi di costituzione delle servitù prediali, Napoli, I 947, I 3-I 5; SolazzI, S., "Sul principio 'Nemini res sua servit", Studia et documenta historiae et iuris, Ciudad del Vaticano, I 8, I952, 224 y 225; BIONDI, B., Le servitù prediali nel diritto romano, Milano, Giuffrè, $1969^{2}$, n. $^{\circ}$ 39, I05. Defiende D. 8.2.26 Arangio-Ruiz, V., "Note brevi sulla struttura dei diritti frazionarii", Scritti di diritto romano IV, Napoli, Jovene, I977, 205.

Interesante de destacar es la visión de fondo de Solezzi. A su juicio, lo que los juristas clásicos habrían señalado era que un predio no puede servirse a sí mismo (pues naturalmente un fundo no puede ser dominante y sirviente a la vez). Esta idea se encuentra en D. 8.3.33.I y D. 8.3.3 I, lo que motiva en buena parte que el autor considere genuinas las expresiones alusivas al principio. En cambio, que una cosa propia no pueda servir a su propietario le parece que es una idea que difícilmente expresaron juristas clásicos, dado que las cosas propias por esencia están sujetas a su dueño y le proporcionan variadas ventajas.

3 Así concluye Longo, La categoria, cit., 336, en un trabajo que ha sido calificado como de resultados ya adquiridos por Grosso, G., Le servitù prediali nel diritto romano, Giappichelli, Torino, I969, 4 .

4 Cfr. D. 7.6.5 pr., citado en nota I. Grosso, Le servitù prediali nel diritto romano, cit., 4-Io. Asimismo, concluye de su estudio que las servidumbres personales solo comprendían el uso y el usufructo Longo, La categoria, cit., 337.

5 Biondi, B., Las servidumbres, trad. José Manuel González Porras, de la 2. ed., Granada, Comares, 2002, n. ${ }^{\circ}$ 48, 2 I 3. Señala expresamente como común a la superficie, enfiteusis, prenda e hipoteca, Venezian, Giacomo, Usufructo, uso y habitación, Madrid, Revista de Derecho Privado, I 928 , t. I, n. ${ }^{\circ} 44,90$. 
de otro derecho real distinto al de dominio. Luego, todo derecho real de los llamados modernamente limitados o desmembrados (distinto de la propiedad) son iura in re aliena, en cuanto el titular del mismo y el dueño de la cosa sobre la cual recaen deben ser personas diferentes ${ }^{6}$. El principio aparece explicado tradicionalmente y en particular en las obras decimonónicas 7 bajo la fórmula nemini enim res sua servit iure servitutis, sed prodest iure dominii: las cosas propias no pueden servir a ninguna persona por derecho de servidumbre, sino por derecho de propiedad.

Resultando hoy aplicable igualmente el nemini res sua servit a todos los derechos reales limitados ${ }^{8}$, y habiéndose restringido en los ordenamientos jurídicos actuales el concepto de servidumbre a las solas servidumbres denominadas prediales, preferimos en adelante referirnos al principio con la fórmula nemini res sua servit iure servitutis, utilizada modernamente por algunos autores con la finalidad de precisar que ninguna cosa propia puede servir a su dueño por derecho de servidumbre (descartando la referencia a otros derechos reales limitados) 9 .

El principio fue adoptado por el antiguo derecho español ${ }^{\mathrm{Io}}$, reconocido por los autores que precedieron al $C_{0} d e^{I I}$ y acogido por las codificaciones civiles decimonónicas y la mayoría de las modernas. Esto último mediante la introducción de la "ajenidad" predial como requisito de existencia de las servidumbres,

6 Grosso, Le servitù prediali nel diritto romano, 3 y 89; Grosso, G. y Deiana, G., Le servitù prediali, t. I, Torino, Utet, $1955^{2}$, n. $^{\circ} 9,23$.

7 Escriche, J., Diccionario razonado de legislación y jurisprudencia, t. III, Madrid, I845², voz "servidumbre", 472; Rogron, J. A., Code civil expliqué. Par ses motifs et par ses exemples, Bruxelles, Tarlier, I $829^{5}$, I 4 I.

8 Longo, expresamente, señala que la regla no es una característica de las servidumbres, sino de cualquier ius in re aliena. Porque "la massima romana: nulli res sua servit, a parte il fatto che fu enunciata per le sole servitù prediali, non contiene un concetto teorico indipendente e proprio delle sole servitù, ma è un semplice proverbio pratico: una formula mnemonica": LoNGo, La categoria, cit., 339 .

9 Rebolledo Varela, Á. L. (ed.), Tratado de servidumbres, Navarra, Aranzadi, 20I333, t. I, 52; Del Arco Torres, M. Á. y Pons González, M., Régimen jurídico de las servidumbres, Granada, Comares, 20085, 20.

Io Consagraba el principio Part. 3.3 I.I3: "Pero esto se entiende de aquella servidumbre, que ome pone en su cosa, que sea provechosa al heredamiento, o casa de otri, e non a la suya". Por su parte, Gregorio López expresamente afirmaba en su Glosa: “...quia res sua nemini jure servitutis servit”, citando D. 8.2.26 y D. 7.6.5 pr. aludidos en nota I. LóPez DE Tovar, G., Los códigos españoles: concordados $y$ anotados, M. Rivadeneyra (ed.), t. III, Madrid, Imprenta de la Publicidad, I848.

I I Citando D. 7.6.5 pr. (ver nota I), afirma que uno de los axiomas de las servidumbres es "que toda servidumbre se constituya en cosa ajena, porque a ninguno sirve su cosa", Herneccius, J. G., Elementa ivris romani, Lib. II, Tit. III, \$ ccclXxI, (Compluti, I808); y en Elementa juris civilis secundum ordinem institutionum, Lib. II, Tit. III, \$395 (Neapolis, I 764). Citando D. 8.2.26 y D. 8.4. Io (ver nota I), señala que característica que las distingue es que "en las servidumbres de los fundos la heredad sujeta pertenece siempre a otro dueño distinto de aquella a quien se deben; pues no se llama servidumbre el derecho que tiene el dueño de usar de una fina propia", Dомат, J., Loix civiles dans leur ordre naturel, Lib. I, Tit. XII (Paris, I 7 I3). 
siguiendo como modelo el artículo 637 c.c. fr. ${ }^{\mathrm{I} 2}$. Adicionalmente, se trata de un principio habitualmente reconocido por la doctrina comparada ${ }^{\mathrm{I} 3}$.

El Código de Bello no se apartó ni del citado principio ni del código francés, conceptuando a las servidumbres en los artículos 820 c.c. chil. y 879 c.c. col. como "un gravamen impuesto sobre un predio en utilidad de otro predio de distinto dueño". Asimismo, tanto la doctrina chilena como la colombiana han admitido desde los inicios de la vigencia del código civil al nemini res sua servit iure servitutis como principio base de las servidumbres y de su reglamentación ${ }^{\mathrm{I}}$.

El fundamento jurídico que sustenta el principio en comento es muy natural. El propietario no necesita para el uso y goce de la cosa objeto de su dominio de la constitución de otros derechos reales sobre ella. Es el mismo dominio el que le otorga todas y cada una de las facultades que pueden ejercerse a su respecto, con la sola limitación de la ley y de los derechos ajenos (arts. 582 c.c. chil. y 669 c.c. col.). No en vano los derechos reales han sido calificados como derechos "desmembrados del dominio". De ahí que cualquier utilidad que una servidumbre pudiera jurídicamente otorgarle al propietario, este la obtiene antes como dueño ${ }^{15}$. Así por ejemplo, no necesita el titular de la propiedad de una servidumbre de tránsito para pasar de un extremo de un predio que le pertenece al extremo opuesto de otro predio vecino también propio. Igualmente, no necesita de una

I 2 Art. 637. "Une servitude est une charge imposée sur un béritage pour l'usage et l'utilité d'un béritage appartenant à un autre propriétaire”.

I $3 V$.gr., en España, Rebolledo, Tratado de servidumbres, cit., t. I, 52; Díaz Fuentes, A., Servidumbres, serventías y relaciones de vecindad, Barcelona, Bosch, 2004, 52. En México, cuyo código del DF sigue en la materia la normas españolas, Rojina Villegas, R., Compendio de derecho civil, México D. F., Porrúa, $20155^{45}$, n. ${ }^{\circ}$ 3, I40; DE Ibarrola, A., Cosas y sucesiones, Porrúa, México D. F., 2004 ${ }^{\mathrm{I} 4}$, n. ${ }^{\circ}$ 8i9, 587; De la Mata Pizaña, F. y Garzón Jiménez, R., Bienes y derechos reales, México D. F., Porrúa, 20 4 47 375. En Italia, Grosso y Deiana, Le servitù prediali, cit., n. ${ }^{\circ}$ 9, 23 ss.; Spanò, G. y Caruso, S., Le servitù prediali, Milano, Giuffrè, 2013, I82; Burdese, A., Le servitù prediali, Linee teoriche e questioni pratiche, Padova, Cedam, 2007, I4. En Francia, Terré, F. y Simler, P., Droit civil: Les biens, Dalloz, Paris, $2014^{9}$, n. ${ }^{\circ} 870,773$; Beauvarlet, P., Les servitudes, Paris, Defrénois, 20I3, I 5 .

I4 En Chile, Chacón, J., Estudio comparativo del código civil chileno, t. II, Santiago, Imprenta Nacional, I8903, 407; Claro Solar, L., "La destinación del padre de familia como título de la servidumbre voluntaria", Revista de Derecho y Zurisprudencia, Santiago, I9, I922, I. a parte, 63. Puede verse también este artículo en Tavolari, R. (ed.), Doctrinas esenciales, Derecho civil, Bienes, Revista de Derecho y Jurisprudencia, Edición Bicentenario, Santiago, Puntolex, 2010, 74I ss.; Claro SoLAR, L., Explicaciones de derecho civil chileno y comparado, De los bienes, Santiago, Jurídica de Chile, 2015 , vol. iv, t. 9. ${ }^{\circ}$, n. ${ }^{\circ}$ I 3 I 7, 30 y 3 I; Varas Videla, E., De las servidumbres, tesis de grado para optar al título de licenciado, Universidad de Chile, Santiago, I925, 393 y 394. En Colombia, Velásquez Jaramillo, L. G., Bienes, Bogotá, Temis, $2014^{\text {I3 }}$, 4I I ; Arévalo Guerrero, I. H., Los bienes, Constitucionalización del derecho civil, Bogotá, Universidad de Externado de Colombia, Bogotá, 238.

I 5 "El uso de estos servicios se hace en base a la titularidad dominical de su propietario y el alegar un derecho de servidumbre no tiene sentido, ya que carece de un contradictor, de un interés o una voluntad ajena que se le imponga para que use en esta o en aquella forma": BonET Correa, J., La constitución de las servidumbres por signo aparente, Madrid, Consejo Superior de Investigaciones Científicas, I970, I34. 
servidumbre de acueducto para extraer y conducir agua desde uno de dichos predios al otro que carece de ella. En todos estos casos obtiene el beneficio iure proprietatis y no iure servitutis.

A lo anterior los doctrinarios han ido añadiendo argumentaciones que refuerzan la regla. Así, Biondi plantea que la exigencia de pertenecer los predios a distintos dueños deriva de la misma noción de relación jurídica. Ninguna persona puede al mismo tiempo ser titular de un derecho y titular del deber correlativo pues, aunque se diga que la relación es entre fundos, lo cierto es que ella es constituida por personas ${ }^{\mathrm{I} 6}$. Y tiene en efecto mucha razón el autor italiano. No obstante, las servidumbres son definidas por el código civil con base en el vínculo predial (arts. 820 c.c. chil. y 879 c.c. col.), recordando la época en que el dominio se confundía materialmente con el predio, y las servidumbres con este; lo cierto es que las "servidumbres activas" constituyen un derecho real que el propietario del predio dominante tiene sobre el predio sirviente (arts. 577 c.c. chil. y 665 c.c. col.). Luego, desde la perspectiva pasiva, lo gravado en definitiva no es el predio sirviente, sino el dominio de su propietario, motivo por el cual se considera a las servidumbres una limitación del dominio (arts. 732 n. ${ }^{\circ} 3$ y 793 n. ${ }^{\circ}$ 3 c.c. col.). De manera que quien ejerce el derecho real de servidumbre y ejercita las facultades que este otorga, es el dueño del predio dominante; y quien tiene los deberes correlativos de dejar hacer, no hacer o excepcionalmente de hacer

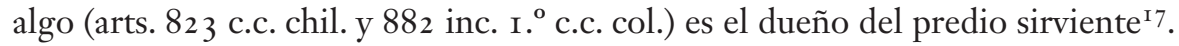
En conclusión, si hubiera coincidencia en la titularidad del predio dominante y del predio sirviente significaría que se está en presencia de una persona que es acreedora y deudora de sí misma.

El principio nemini res sua servit iure servitutis no es solo una mera declaración abstracta, sino que tiene efectos jurídicos relevantes tanto respecto al origen de las servidumbres como respecto a su extinción, los que son consagrados habitualmente por las regulaciones legales civiles.

En cuanto al origen de las servidumbres voluntarias, el citado principio excluye la constitución de servidumbres mediante acto jurídico unilateral del propietario $^{\mathrm{I} 8}$. Aunque sea su voluntad, el dueño no puede constituir una servidumbre entre dos predios que le pertenecen o entre dos partes de un mismo predio bajo su dominio. El acto, no obstante se otorgue mediante escritura pública,

I6 BIondi, Le servitù prediali, cit., n. ${ }^{\circ}$ 39, Io4.

I 7 Reafirman precisamente el carácter de derecho real como poder inmediato sobre la cosa erga omnes, limitante del dominio del predio sirviente, Grosso y DeIana, Le servitù prediali, cit., n. ${ }^{\circ}$ I I y I 2,28 ss.

I 8 Estimamos unánime la doctrina en este sentido. Ello aun cuando siempre es posible encontrar en alguna latitud una opinión en contrario. Es el caso por ejemplo de Rojina, en México, quien admite la constitución de servidumbres por acto unilateral. RoJina, Compendio de derecho civil, cit., I 44. Sin embargo, es una opinión poco fundada y aislada. En sentido contrario, DE La Mata y Garzón, Bienes y derechos reales, cit., 383; De Ibarrola, Cosas y sucesiones, cit., n. ${ }^{\circ}$ 864, 6 I 3 . 
no producirá el efecto constitutivo esperado, por no concurrir el requisito de la ajenidad. De ahí que tradicionalmente la doctrina haya especificado como título "entre vivos" constitutivo de servidumbres sólo a la "convención" I9.

El tenor de la primera parte de los artículos 880 c.c. chil. y 937 c.c. col. pareciera contradecir lo anterior, al disponer que "Cada cual podrá sujetar su predio a las servidumbres que quiera...”. Como se aprecia, la literalidad daría pie para pensar en la admisión en nuestros códigos de la constitución unilateral de servidumbres. Sin embargo, una lectura como esta debe descartarse. Primero, porque estaría en contradicción con el principio nemini res sua servit iure servitutis. Segundo, porque la disposición alude claramente a los propietarios de eventuales "predios sirvientes", en cuanto pueden aceptar gravar ("sujetar") su predio en favor de un predio dominante con todas las servidumbres que quieran, rechazando una imposición por parte del propietario de este último (lo que lleva a la necesidad de que concurran ambas voluntades). Tercero, porque el artículo debe relacionarse con los artículos 820 c.c. chil. o 879 c.c. col., los cuales consagran como requisito esencial para que exista una servidumbre la "ajenidad" de los predios. Y cuarto, porque el efecto constitutivo de una servidumbre voluntaria cuya fuente sea un título tiene lugar no por el otorgamiento de este, sino por la tradición del derecho real respectivo a la luz de los artículos 698 c.c. chil. y 760 c.c. col. ${ }^{20}$; acto jurídico

i9 P. ej., en Chile, Vodanovic Haklicka, A., Tratado de los derechos reales, versiones de clases escritas de los profesores Alessandri, Arturo y Somarriva, Manuel, t. II, Santiago, Jurídicas de Santiago, $20167{ }^{\text {, n. }}{ }^{\circ}$ I I 54, 227 ; Claro Solar, Explicaciones, cit., vol. iv, t. 9. ${ }^{\circ}$, n. ${ }^{\circ}$ I632, 282 ; Jorquera Carvajal, M., De las servidumbres (Título XI - Libro 2. ${ }^{\circ}$ C. Civil), tesis de grado para optar al título de licenciado, Universidad de Chile, Valparaíso, Imprenta Comercial, I937, 44; VAras, De las servidumbres, cit., 399. En Colombia, Velásquez, Bienes, cit., 420.

20 Es evidente que en estos artículos, o bien existe una sinonimia entre "constitución" y "tradición" de las servidumbres, o bien a la "constitución" se le aplica el estatuto de la "tradición". La expresión "el tradente exprese constituirlo" de los artículos 698 c.c. chil. y 760 c.c. col. deja a la vista que en realidad el tradente es un "constituyente". Conceptualmente no existe diferencia entre Chile y Colombia por el hecho de que la tradición se haga de distinta manera (por escritura pública en el primer país, por inscripción en el segundo).

Ahora bien, que sea la tradición la que produce el efecto constitutivo de la servidumbre y no el otorgamiento del título es una consecuencia del sistema adquisitivo de nuestros ordenamientos: título y modo. Asimismo, que en materia de servidumbres tenga lugar la "constitución" en vez de la tradición propiamente tal, se debe a que el derecho real de servidumbre activa ya constituido no puede transferirse independientemente, en virtud de la inseparabilidad de las servidumbres del predio al que activa o pasivamente pertenecen, de acuerdo a los artículos 825 c.c. chil. y 883 c.c. col., que consagran precisamente el principio de la indivisibilidad de las servidumbres. La doctrina está de acuerdo en que es la tradición la que produce el efecto constitutivo de la servidumbre y no el otorgamiento del título. $V . g r$., en Chile, Claro Solar, Explicaciones, cit., vol. Iv, t. 9, n. ${ }^{\circ}$ I632 y I633, 282 y 283; San Martín Devoto, Diego, Las servidumbres, Santiago, Conosur, I998, I29; PeÑallillo Arévalo, Los bienes, Santiago, Jurídica de Chile, 2006, 504. Este último critica por lo dicho la referencia a "tradición" en el artículo 698, aunque da lo mismo porque, después de constituido el derecho real, nunca podrá tener lugar verdadera tradición. En Colombia, Velásquez, Bienes, cit., 420 y 42 I; Ternera Barrios, F., Derechos reales, Bogotá, Temis, $2015^{4}, 339$. No han faltado las opiniones históricas discordantes, en orden a que la constitución de servidumbres voluntarias no requeriría de tradición. Así, Jorquera, De las servidumbres, cit., 44. 
de carácter bilateral que exige la comparecencia de dos partes $^{2 \mathrm{I}}$, con lo cual se excluyen inmediatamente los actos unilaterales.

La única aparente excepción que se admite desde el derecho romano ${ }^{22}$, por expresa disposición legal en algunos códigos modernos ${ }^{23}$, por la doctrina chile$\mathrm{na}^{24}$, colombiana ${ }^{25}$ y comparada ${ }^{26}$, es el caso del testamento ${ }^{27}$. A través de este, el dueño de dos predios puede asignarlos mortis causa a personas distintas como legados y disponer el establecimiento de servidumbres entre ellos que favorecerán a un asignatario y perjudicarán a otro (lo mismo respecto de partes de un predio). Empero, si bien estamos en presencia de un acto unilateral, la constitución de la servidumbre no se producirá sino hasta la muerte del testador (aceptados claro está los legados por los legatarios respectivos y cumplidas las eventuales condiciones que pudo haber introducido el testador). Concurriendo estas circunstancias, encontramos a un titular de un predio al cual activamente le pertenecerá un derecho real de servidumbre y a un titular de un predio que pasivamente soportará el gravamen. Es decir, estamos en presencia de dos predios de distintos dueños, que adquirieron a título singular por sucesión por causa de muerte la propiedad de cada uno de ellos ${ }^{28}$, y, por ende, nos encontramos ante el efectivo cumplimiento del requisito de la ajenidad establecido en los artículos 820 c.c. chil. y 879 c.c. col.

La imposibilidad de constituir servidumbres voluntarias entre predios propios o entre partes de un mismo predio propio mediante acto jurídico unilateral no excluye la posibilidad para el propietario de establecer servicios entre dichos

2 I Ver arts. 670 c.c. chil. y 740 c.c. col.

22 Ver I. 2.3.4.

$23 V$.gr., art. I 547 c.c. port. de I966 (aunque ya reconocido en el art. 2275 del texto de I868); art. I 378 c.c. br.; art. i i 8 I c.c. de Quebec.

24 Barcia Lehmann, Lecciones de derecho civil chileno. De los bienes, t. iv, Santiago, Jurídica de Chile, 2008, i 95 y en Barcia Lehmann, R., Código Civil. Doctrina y jurisprudencia, t. I, Santiago, Thomson Reuters, 2010, 793; PeÑallillo, Los bienes, cit., 502; Claro Solar, Explicaciones, cit., vol. iv, t. 9. ${ }^{\circ}$, n. ${ }^{\circ}$ I632, 282; Vodanovic, Tratado de los derechos reales, cit., n. ${ }^{\circ}$ I I 54, 227 ; SAn MARTín, Las servidumbres, cit., I 29; VARAs, De las servidumbres, cit., 399; Así, Jorquera, De las servidumbres, cit., 44 .

25 VELÁsquez, Bienes, cit., 420.

$26 V$.gr., en España, Rebolledo, Tratado de servidumbres, cit., t. I, I 83. En Italia, Spanò y Caruso, Le servitù prediali, cit., 490. En Francia, Terré y Simler, Droit civil: Les biens, cit., n. ${ }^{\circ} 888,784$.

27 Si bien no hay una disposición en nuestros ordenamientos que expresamente trate la cuestión, la hipótesis queda comprendida por una parte en la posibilidad admitida por el legislador de legar derechos (arts. i 27 c.c. chil. y i i 85 c.c. col.) y, por otra, en la circunstancia de que en caso de no establecer el testador servidumbres cuando lega porciones de un mismo predio a distintos legatarios es la ley la que impone las servidumbres que sean necesarias para el goce o cultivo (arts. i 20 c.c. chil. y i 78 c.c. col.).

28 Cfr. con arts. 588, 95 I, 952, 954, 956, г 097, I I04, I 239 y I 338 c.c. chil. (arts. 673, I008, I009, IOI I, IOI3, I I 55, I I62, I 296 y I 395 c.c. col.). Particularmente relevantes los dos últimos, en cuanto retrotraen la adquisición del dominio de los predios al momento en que fue deferida la herencia. 
predios o partes, y que a tales servicios se les reconozca existencia. Es lo que ocurriría en los ejemplos dados en precedencia, como serían el establecimiento de un servicio de tránsito o de conducción de agua. Estos, así como una infinidad de otros servicios, pueden ser establecidos entre predios o entre partes de un predio por el dueño, precisamente en el ejercicio de las facultades de gozar y disponer de la cosa que el dominio le concede. Mas, lo relevante está en que el establecimiento de tales servicios no comportará la constitución jurídica de servidumbres voluntarias, sino sólo destinaciones de hecho realizadas en el marco del ejercicio del dominio. Desde el punto de vista del derecho, los servicios quedan comprendidos en la propiedad del titular.

La situación antes descrita tendrá lugar al menos hasta que no concurra la ajenidad de uno de los predios o de una parte del predio. De manera que si el propietario enajena a un tercero uno de los predios, o una de las partes entre las cuales estableció un servicio, o bien, después de fallecido, se adjudican a propietarios diferentes los predios o partes de los inmuebles en una partición, y se cumplen los demás requisitos establecidos por la ley, el servicio de hecho establecido por el propietario anterior adquirirá el carácter de servidumbre. Ello en virtud del modo de constituir servidumbres denominado destinación del padre de familia, consagrado en los artículos 88 I c.c. chil. y 938 c.c. col. ${ }^{29}$. Al respecto, la doctrina nacional expresamente ha destacado como fundamento de este modo constitutivo de servidumbres el principio nemini res sua servit iure servitutis ${ }^{\circ}$.

Finalmente, en cuanto a la extinción de las servidumbres (entre ellas las voluntarias), dado que no pueden existir derechos reales sobre una cosa propia en favor de su propietario, la reunión perfecta e irrevocable de la propiedad de los fundos entre los cuales hay constituida una servidumbre en manos de una misma persona, extingue la servidumbre existente por confusión (consolidación). Ello sin perjuicio de su restablecimiento por los nuevos propietarios y su reconstitución al separase en el futuro los predios nuevamente, o bien del establecimiento de nuevos servicios que se conviertan en servidumbre en idéntica hipótesis. Todo lo expresado según lo dispuesto en los artículos 885 n. ${ }^{\circ} 3{ }^{\circ}$ c.c. chil. y 942 n. ${ }^{\circ} 3$ c.c. $\mathrm{col}^{3}{ }^{\mathrm{I}}$. mente aplicable a otros que tuvieron por fuente la obra de Bello: arts. 883 c.c. salv., 860 c.c. hond. y 925 c.c. ecu.

30 Claro Solar, Explicaciones, cit., vol. iv, t. 9. ${ }^{\circ}$, n. $^{\circ}$ i 638, 286; Vodanovic, Tratado de los derechos reales, cit., t. II, n. ${ }^{\circ}$ I 60 , 230 . En Colombia, citando además expresamente este último libro (que corresponde a las clases de Alessandri y Somarriva), Velásquez, Bienes, cit., 423.

3 I El principio y la extinción por consolidación como efecto del mismo, también opera respecto de los otros derechos reales sobre cosa ajena: usufructo (arts. 806 c.c. chil. y 865 c.c. col.), de uso y habitación (arts. 8 I 2 c.c. chil. y 87 I c.c. col.), de prenda (arts. 2406 c.c. chil. y 243 I c.c. col.); y, aunque no lo dice expresamente el artículo 2434 c.c. chil. ( 2448 c.c. col.), la doctrina ha estado de acuerdo en que se extingue el derecho real de hipoteca, como ocurre con la prenda, cuando el acreedor hipotecario adquiere el dominio de la cosa hipotecada. Así Somarriva Undurraga, M., 


\section{Las excepciones modernas al principio nemini res sua servit iure servitutis}

Si bien algunos casos en derecho romano suelen ser citados como posibles excepciones al principio, y sin perjuicio de resultar discutible tal excepcionalidad ${ }^{32}$, ellos no significaron la introducción de alteraciones al mismo. Por el contrario, como se ha dicho, el principio fue recogido incólume en las codificaciones decimonónicas, sin perjuicio de algunas leves atenuaciones en ambientes germánicos 33 .

Sin embargo, a fines del siglo xıx la situación empieza a cambiar. Frente a la teoría y a la regulación tradicional, comenzaron a surgir en Europa verdaderas excepciones, admitiéndose la posibilidad de constituir servidumbres sobre predio propio. Ello ha llevado a la existencia de las llamadas "servidumbres de propietario".

Fundamentales en la materia resultaron el pensamiento y los trabajos de Eugen Huber ${ }^{34}$, quien además redactaría el código civil suizo de i907. Precisamente, este admite la constitución de servidumbres por acto unilateral del propietario ${ }^{35}$ y su vigencia aun después que la propiedad de dos fundos se consolide en manos de un propietario ${ }^{36}$. Huber defiende la posibilidad de constituir derechos reales sobre cosa propia, en razón de que ellos se explican como partes del contenido del derecho de propiedad, las que se desprenden de este para satisfacer una necesidad económica del propietario. Luego, si la constitución de un derecho real favorece económicamente al dueño, debe permitírsele y, por el contrario, no prohibírsele. En todo caso, admite que debe reconocérsele la facultad señalada al propietario solo si lo exigen las necesidades económicas, correspondiéndole a la ley decidir cuándo ello ocurre ${ }^{37}$.

La admisión de las servidumbres de propietario también se logró en Alemania, aunque de una manera bastante singular, pues el texto del вGB no las contempla, siendo aquellas solo el resultado de la interpretación jurisprudencial

Tratado de las cauciones, Santiago, Nascimiento, i943, n. ${ }^{\circ}$ 466, 474 y 475; Lecaros Sánchez, José Miguel, Las cauciones reales. Prenda e hipoteca, Santiago, Metropolitana, 2009² , n. ${ }^{\circ}$ I 82, 403.

32 Uno de los casos más citados como excepción es el de D. 8.3·33.r. Véase sobre el particular Biondi, Le servitù prediali, cit., n. ${ }^{\circ}$ 39, I07, y n. ${ }^{\circ} 82,23$ I.

33 Ver Huber, E., Die eigentümerdienstbarkeit, ein Beitrag zu ibrer Rechtfertigung, Bern, Stämpfli \& Cie, I902, 5 I ss.

34 Principalmente en la obra citada en nota precedente.

35 Art. 733: "El propietario puede constituir sobre su fundo una servidumbre en favor de otro fundo suyo".

36 Art. 735: "I. Cuando los dos predios son reunidos en una misma mano, el propietario puede cancelar la servidumbre. 2. La servidumbre subsiste como derecho real en tanto la cancelación no tenga lugar".

37 Huber, E., Los derechos reales en el derecho privado suizo. Los preceptos de forma en el derecho privado suizo, trad. Enrique Ramos, Centro de Estudios Históricos, Madrid, I9 19, 56. 
y doctrinaria. La base de dicha interpretación fue por una parte la no referencia del código alemán al requisito de la "ajenidad" en el concepto de servidumbres contenido en el parágrafo ı ı 8; y por otra, la no extinción de la servidumbre por consolidación según el parágrafo 889. A partir de lo anterior, la conclusión de que el вGв admitía la existencia de servidumbres entre predios propios sería fácil de alcanzar. El único obstáculo lo constituía el parágrafo 873 que exige expresamente acuerdo "entre las partes" para la constitución de un derecho real sobre una finca. Un fallo del Tribunal Supremo de I933, cimentado en los dos primeros parágrafos citados, interpretó que en caso de necesidad económica del propietario podía sustituirse dicho acuerdo bilateral por una declaración unilateral de este ante el Registro de propiedad $3^{8}$. Con ello, la conclusión que podía obtenerse de los parágrafos ı о 8 y 889 resultó ratificada.

Interesante es el caso de España, que ha vivido en los últimos años un proceso de recodificación por vía de las comunidades autónomas, distanciándose en varias materias del código civil estatal. Una de estas es la de las servidumbres y la cuestión que tratamos. Así, tanto el Código de Cataluña39 como el Código Foral de Aragón $4^{\circ}$ han incorporado expresamente la constitución de servidumbre sobre finca propia. Con una redacción menos clara, la misma posibilidad admitiría la Ley Civil de Galicia4 ${ }^{\mathrm{I}}$.

América no ha sido ajena al fenómeno. Así Perú, siguiendo el código suizo, introdujo la excepción en su código de I936 mediante el artículo 977 ${ }^{[42]}$, el cual fue reproducido en el artículo ro48 del nuevo código de i984. A su vez Guatemala copió la primera disposición peruana en el artículo $75^{2}$ inciso $2 .^{\circ}$ de su código ${ }^{43}$. La tendencia también fue acogida en Venezuela mediante el artículo 72 I

$3^{8}$ Ver Mateo Bonge, I., La servidumbre de propietario, Madrid, Marcial Pons, 200o, 48 , nota n. ${ }^{\circ} 82$ (autores alemanes que sostienen esta forma de constitución de servidumbres en 77 , nota n. ${ }^{\circ}$ I 86 ); García Alguacil, M. J., Consolidación y derechos reales en cosa propia, Granada, Comares, 2002, I 2 I-I 23; Hedemann, J. W., Derechos reales, trad. José Luis Díez Pastor y Manuel González Enríquez, vol. II, Madrid, Revista de Derecho Privado, I955, 350 y 35 I.

39 Art. 566-3.r: "Servidumbre sobre finca propia. I. El propietario o propietaria de más de una finca puede constituir entre estas las servidumbres que considere convenientes".

40 Art. 564: "Servidumbre sobre finca propia. I. Es posible constituir servidumbre sobre finca propia, quedando su efectividad subordinada a que la finca dominante o la sirviente cambien de titularidad".

4I Art. 87.I: "Todo propietario de un predio puede establecer sobre el mismo, por actos inter vivos o mortis causa, las servidumbres de paso que considere convenientes, siempre que no contravenga las leyes y el orden público".

42 Art. 977: "El propietario de dos predios, puede gravar el uno con servidumbres en beneficio del otro".

43 Art. 752: "Servidumbre es el gravamen impuesto sobre un predio para uso de otro predio de distinto dueño o para utilidad pública o comunal.- Sin embargo, el propietario de dos fincas puede gravar una de ellas con servidumbre en beneficio de la otra". 
inciso 2. ${ }^{\circ}$ del código de $\mathrm{I}_{942}{ }^{[44]}$ y por el estado canadiense de Quebec por medio de su artículo I $183^{[45]}$.

En los casos anteriores, las leyes civiles introducen en definitiva una nueva institución que permitiría con carácter general la constitución de servidumbres por acto jurídico unilateral, contradiciendo el principio nemini res sua servit iure servitutis.

A ellos hay que adicionar las disposiciones especiales, mediante las cuales el legislador permite de manera expresa, si bien excepcional, tal posibilidad, aun cuando la servidumbre de propietario como tal no se encuentre reconocida en el respectivo ordenamiento jurídico. Ejemplo en Chile de esta situación han sido las servidumbres de alcantarillado, constituidas por el urbanizador y dueño del terreno en que se construirá un conjunto habitacional a través de escritura pública, las cuales adquieren el carácter de tal por la sola disposición de la ley, si el plano es aprobado por la autoridad administrativa competente. Como se advierte, la servidumbre existirá aun cuando no se haya enajenado vivienda alguna y continúe como titular de todas las partes del predio el único dueño original o quien le suceda en tal calidad 46 .

Igualmente, en principio deberían sumarse los casos en que de forma implícita el legislador parece admitir la constitución de servidumbres por acto unilateral. Se trata de servidumbres que las leyes o reglamentos establecen como un requisito habilitante para la disposición material y jurídica de inmuebles, pero no se imponen por el sólo ministerio de la ley al propietario ni pueden exigirse judicialmente, quedando entregada a la voluntad de aquel la constitución conforme a sus intereses. Coinciden entonces con la definición de servidumbres voluntarias de los artículos 83 I c.c. chil. y 888 c.c. col., en cuanto "son constituidas por un hecho del hombre", mas la libertad de los dueños se encuentra limitada, pues se

44 Art. 72 I: "La destinación del padre de familia procede solamente respecto de las servidumbres aparentes, continuas o discontinuas y cuando consta, por cualquier género de prueba, que dos fundos actualmente divididos han sido poseídos por el mismo propietario, y que éste ha puesto o dejado las cosas en el estado del cual resulta la servidumbre.- También podrá el propietario de dos predios gravar con servidumbre de cualquier especie, uno de ellos en beneficio del otro, siempre que lo haga en escritura protocolizada en la Oficina Subalterna de Registro a que corresponda la ubicación de los inmuebles.- Si los dos predios dejan de pertenecer al mismo propietario, en uno cualquiera de los casos señalados en los dos párrafos anteriores, sin ninguna disposición relativa a servidumbre, ésta se reputa establecida activa y pasivamente sobre cada uno de dichos predios".

45 Art. I 83: "La servitude par destination du propriétaire est constatée par un écrit du propriétaire du fonds qui, prévoyant le morcellement éventuel de son fonds, établit immédiatement la nature, l'étendue et la situation de la servitude sur une partie du fonds en faveur d'autres parties".

46 Art. 6. ' Ley 6977: "Cuando la servidumbre consista en el establecimiento de un servicio común de alcantarillado, sea mediante el sistema de red, cámara, desagüe o cualquier otro, proyectado para servir a dos o más viviendas de un conjunto habitacional, se entenderá constituida tal servidumbre, por el solo ministerio de la ley, por el hecho de aprobarse el plano a que se refiere el artículo $3 .^{\circ}$, el que quedará archivado en la oficina de la autoridad competente que lo haya aprobado, sirviendo este hecho como equivalente a la protocolización del respectivo documento". 
ven forzados heterónomamente a su constitución si quieren lograr determinada disposición del predio. De ahí que pueden ser catalogadas de "servidumbres voluntarias forzosas".

Ejemplo actual en Chile es la constitución de servidumbres de tránsito en favor de lotes o unidades interiores resultantes de la subdivisión del terreno o del desarrollo de condominios por parte del propietario de predios urbanos, autorizadas por el director de obras de la municipalidad respectiva, cuando los primeros no tienen acceso directo a camino público 47 . De manera que el propietario que desee disponer de su predio por partes o bien desarrollar en él un proyecto inmobiliario destinado a condominio deberá cumplir con el requisito de la constitución por acto jurídico unilateral de la servidumbre. Pensamos sin embargo que en estas situaciones la excepción es más aparente que real, en vistas de lo que se dirá en el acápite v.

Ahora bien, todas las excepciones reales o aparentes al principio nemini res sua servit iure servitutis, generales o particulares, explícitas o implícitas, persiguen y tienen por fundamento la satisfacción de alguna ventaja patrimonial en favor del propietario. En este sentido, las explicaciones de Huber se han mantenido vigentes en el tiempo. Así, entre los principales beneficios económicos destacados por dicho autor y los doctrinarios que le han seguido directa o indirectamente se encuentra el desarrollo de urbanizaciones, loteos o proyectos inmobiliarios en general, lo que impulsó originalmente con más fuerza el tratamiento y aceptación de las servidumbres sobre cosa propia ${ }^{48}$; el cumplimiento de ordenanzas o reglamentos de construcción (como ocurre con los citados ejemplos chilenos); evitar la desvalorización del predio o por el contrario alcanzar la valorización del mismo; lograr una reserva de preferencia frente a hipotecas u otros derechos reales constituidos con posterioridad; obtener ahorros económicos al evitar la extinción por consolidación e incurrir en nuevos gastos de constitución; etc. 49 .

47 Véanse, en materia de subdivisión de predios urbanos, artículos 2.3.6, 3.I.I y 3.4.I de la Ordenanza General de Urbanismo y Construcciones de Chile (Decreto n. ${ }^{\circ} 47$ del MINvu de I992); y en materia de condominios, artículos 9, io y i de la Ley 19537 de 1997 sobre copropiedad inmobiliaria.

48 Los problemas surgidos en el desarrollo urbanístico y en la construcción de barrios constituyen las circunstancias principales sobre las cuales estructura su trabajo Huber, Die eigentümerdienstbarkeit, cit., 9 ss.

49 Enneccerus, L.; Kipp, T. y Wolff, M., Tratado de derecho civil, Derecho de cosas, t. 3, vol. II, trad. Blas Pérez y José Alguer, Barcelona, Bosch, I98 I ${ }^{3}$, 45; Huber, Die eigentümerdienstbarkeit, cit., 73; Cuadrado Pérez, C., La servidumbre de propietario, Madrid, Colegio de Registradores de la Propiedad y Mercantiles de España, 2008, I 47 ss.; MATEo, La servidumbre de propietario, cit., 82, I 57 SS.; Llácer Matacás, M. R., "La servidumbre sobre finca propia”, en Rebolledo, Tratado de servidumbres, cit., t. II, 27I; Arjona Guajardo-Fajardo, J. L., "El derecho de vuelo en nuestro ordenamiento (consideraciones a propósito de unas recientes resoluciones)", Revista Crítica de Derecho Inmobiliario, Madrid, 664, 200 I, 69 I; García Alguacil, Consolidación y derechos reales en cosa propia, cit., , 05. 


\section{La destinación del padre de familia (DPF): el "servicio aparente"}

Destacábamos en el acápite I la íntima relación entre el principio nemini res sua servit iure servitutis y la DPF, dada por la circunstancia de que si bien el propietario se encuentra imposibilitado de constituir servidumbres unilateralmente, al menos puede en razón de su derecho de propiedad establecer servicios entre partes de un predio, o entre los predios objeto de su dominio, de modo que una vez enajenada una de las partes o uno de los predios según el caso, el servicio establecido de hecho se transformaba en una relación de derecho entre los predios (servidumbre). Ello en virtud del modo de constituir servidumbres denominado DPF, regulado en los artículos 88 I c.c. chil. y 938 c.c. col.

Ahora bien, la DPF tiene como base fáctica la conservación del estado de cosas establecidas entre predios o partes de un predio pertenecientes a un mismo dueño por este, después de la enajenación o adjudicación a un tercero de uno de los predios o partes de un predio. Dicho estado de cosas corresponde al establecimiento de un servicio dispuesto por el dueño, en el ejercicio del dominio del cual es titular. La conservación comporta, por disposición legal y no existiendo voluntad expresa en contrario, la continuación de dicho servicio en calidad de servidumbre luego de la enajenación o adjudicación.

Para que la conservación del estado de cosas señalada pueda tener lugar es necesario que el tercero adquirente tome conocimiento efectivo o potencial del mismo (scientia). Esto último por cuanto el adquirente podría no haber concurrido materialmente a verificar la situación de hecho de los predios, o bien, habiéndolo hecho, no haber examinado las circunstancias como lo haría un hombre medio, razonable o prudente. Luego, su no presencia o su negligencia no pueden ser alegadas como excusa de la imposibilidad de conocer el respectivo servicio.

Más allá de las teorías que han pretendido explicar el fundamento de la constitución de la servidumbre ${ }^{5}$, presupuesto legal indiscutible que debe concurrir es que no se haya establecido expresamente otra cosa en el título, lo que exige necesariamente el conocimiento del servicio por parte del adquirente o adjudicatario.

Ahora bien, ¿cuáles son los requisitos que debe presentar el estado de cosas para generar el conocimiento referido y que la voluntad resulte objetivamente inequívoca? Por una parte, el servicio debe ser aparente; y por otra, el servicio debe ser permanente, requisito al que los autores también aluden con los térmi-

50 Sobre las distintas teorías acerca de la naturaleza jurídica de la institución, entre las que destacan la voluntarista y legalista, ver CuAdrado Pérez, C., Constitución de servidumbre por signo aparente, Madrid, Cuadernos de Derecho Registral, 2007, 2 I 7 ss.; Guilarte Gutiérrez, V., La constitución voluntaria de servidumbres en el derecho español, Madrid, Montecorvo, I984, 470 ss. 
nos perpetuo, estable o continuo. Históricamente la doctrina ha sido unánime al respecto, no obstante las diferencias de época o la forma de expresarlo ${ }^{5}$.

Precisamente, los artículos 88 I c.c. chil. y 938 c.c. col. establecen como requisitos esenciales de la destinación del padre de familia que el "servicio sea continuo y aparente".

Respecto al carácter continuo, ha constituido un gran error la identificación que han hecho la doctrina y la jurisprudencia tradicionales entre "servicio continuo" y "servidumbre continua". La "continuidad", confundida en el código civil con la "posesión continua", no es un requisito que pueda aplicarse a la DPF. Es más, ni siquiera este modo constitutivo exige posesión, esto es, el "ejercicio" efectivo del servicio que constituiría sustancialmente el derecho de servidumbre respectivo. La DPF lo que requiere son los signos externos que den cuenta de la posibilidad de ejercer el servicio, pero no que actualmente se esté realizando. Incluso, ni siquiera es necesario que las obras a través de las cuales se ejercerá el servicio estén terminadas, lo que ratifica que la posesión o ejercicio de lo que constituiría una servidumbre, de no ser por la titularidad del dominio de ambos predios en cabeza de una misma persona, no es un requisito de este modo de constituir servidumbres. Salvo alguna equívoca opinión aislada $5^{2}$, en esto la doctrina autorizada es unánime 53 .

El requisito que sí debe concurrir, y al cual los artículos 88 I c.c. chil. y 938 c.c. col. no se refieren, es, como señalaba, el de la "permanencia". En este sentido, es de aplaudir el legislador nicaragüense, el cual dispuso expresamente como requisito "señales aparentes y permanentes" 54 . De ahí que no es posible sino entender que "servicio continuo", en las disposiciones citadas, corresponde en realidad a "servicio permanente". Sobre el particular, me remito a otro trabajo en que se aborda en profundidad esta cuestión 55.

5 I No debe ser una distribución pasajera ni objeto de una utilidad momentánea, decía Pardessus, J. M., Trattato delle servitù, trad. R. Mercurio, de la 2..$^{a}$ ed., Napoli, I832, n. ${ }^{\circ}$ 288, I86; Butera, A., "Delle servitù stabilite per fatto dell'uomo", en Il diritto civile italiano, Delle servitù prediali, vol. 3, Torino, Utet, I923, n. ${ }^{\circ}$ 204, 399 y 400; Branca, G.. "Servitù prediali", en Galgano (ed.), Commentario del Codice Civile Scialoja-Branca, Libro Terzo, Bologna-Roma, Zanichelli y Foro Italiano, reimpr., Milano, I999, 32 I; Biondi, Las servidumbres, cit., n. ${ }^{\circ}$ I 54, 663; Tú Faúndez, M., "Mediante signo aparente (o 'por destinación del padre de familia')", en Cerdeira Bravo de Mancilla, G. (ed.), Tratado de servidumbres, Madrid, La Ley, 2015, 590.

52 Tur, Mediante signo aparente, cit., 593.

53 Biondi, Las servidumbres, cit., n. ${ }^{\circ}$ i 54, 665; Branca, Servitù prediali, cit., 322; Guilarte, La constitución voluntaria de servidumbres, cit., 409; Reвоlledo, Tratado de servidumbres, cit., t. I, Iо8.

54 Art. I 573 c.c. nic.: "Si en dos predios del mismo dueño hubieren [sic] señales aparentes y permanentes, puestas por él, en uno o en ambos, que demuestren servidumbre del uno para el otro, esas señales se tendrán como prueba de servidumbre cuando los dos predios pasaren a poder de distinto dueño, salvo si al tiempo de la separación se hubiere dispuesto otra cosa".

55 Rosso Elorriaga, G. F., "Las servidumbres discontinuas pueden adquirirse por 'destinación del padre de familia'. Reinterpretación del artículo 88I del código civil”, en Estudios de derecho 
En cuanto a la necesidad de que la destinación del propietario sea un "servicio aparente", no existen dificultades dogmáticas para su identificación conceptual con la "servidumbre aparente", que es por lo demás la interpretación tradicional dada por la doctrina y la jurisprudencia. De ahí que puede aplicarse el artículo 824 c.c. chil. (882 inc. $3 .^{\circ}$ c.c. col.), conforme al cual "aparente" será el servicio "que está continuamente a la vista" o el "que se conoce por una señal exterior".

La doctrina no se ha preocupado por desarrollar en profundidad el requisito, limitándose en Chile simplemente a reproducir el artículo 88 I $^{\left[{ }_{5}^{6}\right]}$ (938 c.c. col.) o bien a dar lacónicas explicaciones recurriendo a las expresiones del mismo código ${ }^{57}$. E igual cosa ocurre en Colombia ${ }^{5}$.

En términos generales, la "apariencia" se trata de un requisito material de la DPF, que corresponde a la percepción a través de los sentidos de obras, instrumentos o signos que dan cuenta de la existencia del servicio, o bien que incitan al futuro adquirente a informarse respecto del mismo. De ahí que tradicionalmente se caracterice a aquellos como "visibles", en cuanto permiten ser captados por el sentido de la vista, o como "externos o exteriores", en cuanto dan cumplimiento a una condición elemental para ser captados por la vista, cual es la de encontrarse en la superficie o en la parte de afuera de los fundos (o de las construcciones de estos). De manera que son tales obras, instrumentos o signos los que constituyen un estado de hecho evidente o patente que da cuenta de la destinación realizada por el dueño, y que objetivamente puede ser apreciada por cualquiera 59.

"La apariencia" entonces dice relación con el requisito de la institución que cumple la función de publicidad que es exigida para la constitución mediante título $^{60}$. Es decir, la apariencia suple aquella función de publicidad respecto de terceros que es cumplida por la escritura pública o por la inscripción o la transcripción (según el ordenamiento jurídico de que se trate), cuando se exigen estas

civil XI, Jornadas Nacionales de Derecho Civil 2015, Universidad de Concepción, Thomson Reuters, en proceso de publicación.

56 Peñallillo, Los bienes, cit., 507; Barcia, Lecciones, cit., I97; Ruz Lártiga, G., Explicaciones de derecho civil, Bienes, t. III, Santiago, Abeledo Perrot, 20 I I, 407; Rozas VIaL, F., Los bienes, Santiago, Conosur, 1998, n. $^{\circ} 398,359$.

57 Así, "que sea conocido por una señal exterior", dice San Martín, Las servidumbres, cit., I 5 o; "aparente, esto es, continuamente a la vista", es la explicación de Claro Solar, La destinación, cit., 7 I; "que la vean, esto es, que sea aparente", Claro Solar, Explicaciones, cit., vol. rv, t. 9. ${ }^{\circ}$, n. $^{\circ}$ I645, 290; "la apariencia impide que las partes ignoren la existencia del servicio", agregando "ante hecho tan notorios", Vodanovic, Tratado de los derechos reales, cit., t. II, n. ${ }^{\circ}$ I I60, 23 I; reproduce las expresiones de este último, Barcia, Código Civil, cit., 795.

58 Velásquez, Bienes, cit., 423.

59 Rebolledo, Tratado de servidumbres, cit., t. I, Io6.

60 Branca, Servitù prediali, cit., 3 I I; Biondi, Las servidumbres, cit., n. ${ }^{\circ}$ 98, 409 y 4io; Díaz, Servidumbres, serventías y relaciones de vecindad, cit., 246; Llácer Matacás, M. R., El título constitutivo de servidumbre en el artículo 54I del código civil, Barcelona, Bosch, I996, 87. 
formalidades como requisito para la constitución de las servidumbres mediante un título. La apariencia, en virtud de su función de publicidad, es la que impide que los adquirentes de uno de los predios o de una de las partes del predio entre los cuales se estableció el servicio o bien sus adjudicatarios ignoren la existencia del servicio ${ }^{6 \mathrm{r}}$.

Ahora bien, históricamente a este requisito se le ha relacionado con una apariencia generada a partir de obras, instrumentos o signos de hecho, de naturaleza exclusivamente material, concurrentes en los predios sirvientes y dominantes respectivos; o en alguno de estos, con los cuales o a través de los cuales se ejerce la servidumbre correspondiente. Ilustración de ello es la redacción que adoptó el artículo Io6r c.c. ital., que exige para dar apariencia a la servidumbre que se trate de "opere visibili e permanenti destinate al loro esercizio". Incluso, se ha desarrollado la idea de que para ser calificado de signo exterior (aquel que da la apariencia) no puede tratarse sólo de señales constituidas por las características físicas de los predios, sino que se requiere de la intervención del hombre; o sea, se debe tratar de obras, instrumentos o signos confeccionados, construidos o puestos allí por el hombre ${ }^{62}$.

El carácter material que debieran tener estas obras, instrumentos o signos es simplemente una herencia histórica, derivada del contexto cronológico en que surgió la institución de la DFP. Sin embargo, en la actualidad es posible también incluir a los instrumentos o signos de hecho pero de naturaleza formal, los que permiten igualmente la configuración de un estado de cosas que da cuenta de la destinación y, por ende, de la existencia del servicio.

En efecto, instrumentos públicos, planos aprobados por órganos públicos, resoluciones administrativas u otros documentos, y sobre todo los registros inmobiliarios, permiten configurar un estado de cosas evidente o patente, accesible y conocible por los terceros. En otras palabras, permiten al propietario efectuar una destinación voluntaria unilateral, cumpliendo con la publicidad necesaria para que cualquier adquirente o adjudicatario conozca la existencia del servicio establecido por el propietario anterior.

Así ocurre con el dueño de dos predios o de uno solo, que decide establecer servicios entre aquellos o sobre una de las partes de este en favor de otra (p. ej., de tránsito), en vistas a una enajenación futura, expresando unilateralmente su voluntad por medio de escritura pública e inscribiendo dicho acto en el registro inmobiliario. Incluso, a menudo el dueño confecciona adicionalmente planos donde consta gráficamente el servicio, el cual también es presentado al órgano

6I Así lo ha reconocido expresamente la jurisprudencia. Casación 3 de septiembre de 2003 , Maldonado Carvajal, R. con Lynch Gaete, E. T., Rol 5167-2002. Legalpublishing, cL/ JUR/4433/2003.

62 Sin perjuicio de ello, da cuenta de casos en que los tribunales españoles han aceptado las simples características físicas del predio RebolLedo, Tratado de servidumbres, cit., t. I, Iо I. 
registrador (Conservador de Bienes Raíces o Registrador de Instrumentos Públicos). En la práctica, y cada vez con más frecuencia, tiene lugar este proceder por parte del único propietario de predios que relaciona a través de servicios. Inclusive, los tribunales chilenos han tenido ocasión de conocer y pronunciarse en casos en que así ocurrióo ${ }^{63}$.

Adicionalmente a hipótesis como la propuesta en precedencia, se suman todas aquellas situaciones en que el propietario de un predio establece servicios entre las distintas partes o lotes o unidades resultantes de una urbanización, loteo o subdivisión que realiza, así como surgidas de la copropiedad inmobiliaria o propiedad horizontal que genera ${ }^{64}$. Servidumbres como las de tránsito, acueducto, ventilación, imposibilidad de construcción sobre una determinada altura, prohibiciones de actividades, imposiciones relativas al ornato, entre muchas otras, resultan hoy de muy frecuente ocurrencia.

En todos los casos anteriores, no obstante haber declarado expresamente su voluntad el propietario, y haber otorgado actos jurídicos unilaterales formales en orden al establecimiento del servicio, no nacería a la vida jurídica ninguna servidumbre, en virtud del principio nemini res sua servit iure servitutis. Ello no obstante, dichos actos jurídicos tampoco se encuentran prohibidos. Por el contrario, se trata de títulos constitutivos, respecto de los cuales aún no habría operado un modo de adquirir, cuya inscripción en los registros inmobiliarios puede entenderse perfectamente amparada por la normativa que regula dichos regis$\operatorname{tros}^{6}$. Incluso más, no parecen en caso alguno contradecir esa normativa, pues

63 Casación io de junio de 20I3, Rojas Devia, O. con Fernández Aguirre, A. y otros, Rol i8 $30-$ 2013, Legalpublishing, CL/JUR/I252/2013.

64 Normalmente los servicios en materia de copropiedad inmobiliaria o propiedad horizontal son establecidos en los reglamentos que el propietario constituyente de este régimen otorga mediante escritura pública. Ver artículos ro y i I de la Ley 19537 de 1997 chilena sobre copropiedad inmobiliaria y artículos $4 .^{\circ}, 6 .^{\circ}$ y $8 .^{\circ}$ de la Ley 675 de 200 I colombiana por medio de la cual se expide el régimen de propiedad horizontal.

65 Los artículos 698 c.c. chil. y 760 c.c. col. distinguen entre título constitutivo y constitución propiamente tal (escritura pública por una parte y tradición por otra), admitiendo que el primero puede ser un acto jurídico distinto a un contrato. $\mathrm{Al}$ respecto véase nota 20. Asimismo, los artículos 883 c.c. chil. y 940 c.c. col. reconocen los títulos constitutivos de servidumbres y que la destinación del propietario sirve precisamente de título constitutivo.

Asimismo, conforme al artículo 53 n. ${ }^{\circ} 2$ del Reglamento del Conservador de Bienes Raíces de Chile de 1857 , puede inscribirse entre otros títulos "todo gravamen impuesto" a los inmuebles "como las servidumbres". Aunque aún no existiría la servidumbre propiamente tal, se trataría de un título constitutivo, que puede dar lugar al nacimiento de la servidumbre cuando concurra además el modo, de lo cual deben tener conocimiento los terceros. De hecho, el n. ${ }^{\circ}$ I del artículo 53 permite inscribir los títulos de derechos reales constituidos sobre inmuebles bajo condición suspensiva, caso en que tampoco hay derecho alguno hasta que la condición se cumpla, no obstante lo cual el Reglamento expresamente permite su inscripción. En todo caso, aun cuando no se aceptara la inscripción, el propietario siempre puede proceder a solicitar el archivo de planos y documentos que llevan los Conservadores de Bienes Raíces conforme lo establecido en los artículos 39, 40 y 85 del citado Reglamento, de todo lo cual se deja constancia mediante anotación al margen de la inscripción de dominio respectiva. 
todas las destinaciones referidas al menos satisfacen una función esencial de los registros, como es la de dar publicidad a los actos relativos a los inmuebles. Adicionalmente, la inscripción en el registro inmobiliario de las destinaciones que los propietarios realizan entre inmuebles bajo su dominio en relación a urbanizaciones, loteos, subdivisiones, copropiedad inmobiliaria o propiedad horizontal tienen como antecedente la mayoría de las veces una resolución administrativa que las aprobó ${ }^{66}$, lo que hace impensable un rechazo de la inscripción por parte del registrador.

Ahora bien, si el servicio se encuentra inscrito en el registro inmobiliario se debería entender necesariamente que está "continuamente a la vista" porque existen señales exteriores que dan cuenta de él, y por tanto que el servicio es aparente, de modo que puede convertirse en servidumbre ipso iure al momento de la enajenación o adjudicación de uno de los predios si no se expresa una voluntad contraria en el título de enajenación o partición; es decir, la destinación formal se convierte en servidumbre si se mantiene el estado de cosas establecidas en el registro público entre los predios o partes de un predio por su único dueño. En otras palabras, podría llegar a constituirse la servidumbre en virtud de los artículos 88I c.c. chil. y 938 c.c. col., lo que comportaría una ampliación del concepto de apariencia, en cuanto incluiría la conservación de los tradicionales signos externos materiales como asimismo de los modernos signos formales.

Ante tal ampliación conceptual del requisito de la apariencia de la DPF, cabe hacer presente que por ningún motivo representaría un obstáculo la circunstancia de que la destinación exista solo formalmente, sin que el servicio haya sido ejercido efectivamente por el propietario pues, como ya se indicó, ni siquiera la DPF material tradicional exige posesión del servicio por parte del propietario. Así como para la DPF material bastan las obras (incluso inconclusas), así también para la DPF formal bastaría la inscripción del servicio en el registro inmobiliario.

Frente a lo expuesto, la cuestión a dilucidar en concreto es si se puede o no admitir esta interpretación que amplía el concepto de apariencia, particularmente en los códigos de Bello. La doctrina no ha profundizado sobre el particular, siendo escasos los pronunciamientos en la materia. Uno de ellos es de Velásquez, quien en un comentario marginal señala a propósito de los grandes

Por su parte, los artículos $2 .^{\circ}$ y $4 .^{\circ}$ del Decreto I 579 de 2012 colombiano sobre el "Estatuto de registro de instrumentos públicos" son lo suficientemente amplios como para admitir la inscripción de instrumentos públicos constitutivos de servidumbres con el objeto de dar publicidad a los mismos. Los instrumentos de que hablamos gravan, limitan, declaran o afectan derechos reales sobre los bienes raíces, o al menos "implican la constitución” de un derecho real.

66 Respecto a Chile, véase nota 47. Respecto a Colombia, estos actos requieren de una licencia del curador urbano, de la autoridad municipal o distrital competente. Véanse los artículos I. ${ }^{\circ}$ a $3 .^{\circ}$ del Decreto I 469 de 2010 , por el cual se reglamentan las disposiciones relativas a las licencias urbanísticas; al reconocimiento de edificaciones; a la función pública que desempeñan los curadores urbanos y otras. Lo anterior sin perjuicio de algunas disposiciones especiales, como el artículo 99 de la Ley 388 de I997 y 2..$^{\circ}$ de la Ley 400 de 1997. 
proyectos inmobiliarios que "su publicidad no está dada por el registro sino por los hechos" ${ }^{6}$, con lo que pareciera abrazar el postulado tradicional, rechazando la nueva interpretación.

Muy distinto a nuestra realidad es el caso de España, donde el problema ha sido una cuestión particularmente madurada y debatida. Así, durante la segunda mitad del siglo xx, diversos autores, y a propósito de variadas circunstancias, plantearon a nivel doctrinario la reconducción de la institución de las servidumbres de propietario vistas hacia la DPF, interpretando ampliamente la expresión "signo aparente" del artículo 54I c.c. esp. (arts. 88 I c.c. chil. y 938 c.c. col. ${ }^{68}$. Esta interpretación fue acogida expresamente por la "Dirección General de los Registros y del Notariado", órgano que procedió a resolver una disputa entre un notario de Valencia y un registrador de propiedad de la misma ciudad, coincidente en buena parte con la hipótesis que tratamos ${ }^{69}$. Así, mediante Resolución de fecha 2 I de octubre de I980, la citada Dirección consideró que nada impide, en relación al artículo 54I c.c. esp., que "pueda ahora dadas las nuevas situaciones planteadas por el urbanismo entender que también puede ese signo aparente crearse en forma documental en la propia escritura pública, y a través de su inscripción en los libros registrales darlo a conocer a terceros, quienes al adquirir todo o parte del inmueble o inmuebles dan lugar a que se cumpla la condición que originará el nacimiento de la mencionada servidumbre"70.

67 VELÁsquez, Bienes, cit., 423, nota I 7.

68 Bonet Correa, José, "La interpretación jurisprudencial y doctrinal del artículo 54I del código civil en la década I987-I997", en Revista de Derecho Privado, Madrid, 2, I999, I07 y Io8; JoRDano Fraga, F., "Prehorizontalidad y servidumbre de propietario", Revista de Derecho Notarial, Madrid, I I 3-I I4, I 98 I 2 23-225; Bonet, La constitución, cit., I 3 I, I 37 y I 39; García García, J. M., "Comentario a sentencia del TS de 2 I octubre 1976", Revista Crítica de Derecho Inmobiliario, Madrid, 529, I978, I2 54; Tamayo, A., El derecho real de servidumbre. Estudio de una revisión del Código Civil en materia de servidumbres, Barcelona, Bosch, I956, 98; DÁvila García, J. y VAlverde Madrid, J., "Comentario a sentencia del TS de I7 de diciembre de I954", Revista de Derecho Notarial, Madrid, 8, I955, 370 y 37 I.

69 La resolución fue emitida en virtud de recurso gubernativo interpuesto por un notario de Valencia, contra la negativa de un registrador de propiedad de la misma ciudad a inscribir una escritura de constitución de servidumbre. Efectivamente, por escritura otorgada ante el notario recurrente, se había procedido a la división de una finca en tres predios, constituyendo entre estos un derecho real de servidumbre de paso, uso y utilización, y de luces y vistas. Las fincas resultantes de la subdivisión se mantenían desde luego bajo el dominio del mismo propietario original. Expresamente se indicó que la servidumbre quedaba desde ese momento regulada como se detalla en la escritura, solicitándose su inscripción en el registro de propiedad, si bien su efectividad quedaba condicionada al cumplimiento del presupuesto establecido en el artículo 54I del código civil, es decir, dualidad de propietarios o copropietarios de predios. El Registrador de la propiedad rechazó la inscripción, entre otras consideraciones, por aparecer constituyendo las servidumbres el único dueño de las fincas, lo que contravenía el artículo 53 o c.c. esp. (que define servidumbre incluyendo el requisito de la ajenidad) sin que se dieran los supuestos de hecho previstos en el artículo 54I.

70 Anuario de la Dirección General de los Registros y del Notariado, año I980, Ministerio de Justicia, Madrid, I98I, parte I, 86 ss. 
En alguna ocasión, el Tribunal Supremo también ha participado de la misma opinión $^{71}$.

Pero esta interpretación del artículo 54I c.c. esp. no es pacífica, pues una buena parte de los doctrinarios españoles especialistas en servidumbres se ha opuesto a ella. Las razones de tal oposición en lo fundamental han sido que: a) la libertad fundaria se presume, de modo que la interpretación de la citada disposición debiera ser restrictiva; b) la base de la DPF serían solo signos u obras materiales; c) en este sentido, "signo aparente" debiera interpretarse a la luz del artículo 532 c.c. esp. como "signos exteriores", cuya naturaleza es material, de modo que no podría calificarse la inscripción en un registro inmobiliario como signo aparente; d) la inclusión de las inscripciones constituiría entonces una aplicación por analogía del artículo 54I, contraviniendo la presunción inicial; y, f) convertir la inscripción en signo aparente sería torcer la mens legislatoris, pues el único medio de publicidad aceptado por la ley serían los actos concretos visibles o tangibles entre fincas y no otras formas de apariencia jurídica, como la inscripciones ${ }^{72}$.

Sin embargo, esta oposición mayoritaria de los autores hispanos se circunscribe solo a la interpretación del artículo 54I, pues no se rechaza la idea de permitirle al propietario establecer unilateralmente servidumbres entre sus predios. Es más, por una parte, ha sido en buena medida la misma doctrina la que ha permitido la admisión de la "servidumbre de propietario" y su inclusión en las legislaciones autónomas vistas en el acápite anterior, introduciendo de esta manera una excepción al principio nemini res sua servit iure servitutis. Por otra, la exclusión de las inscripciones como signo aparente se debe a la idea de que estas se realizarían en realidad sobre la base de un acto jurídico unilateral del propietario que contendría el establecimiento de una servidumbre sujeta a condición suspensiva.

7 I Constaba en la inscripción del registro de la propiedad de una finca subdividida la siguiente referencia: "lindando además interiormente con caminos abiertos en la íntegra de su procedencia para el acceso, comunicación y servicio de las partes en que se fraccione, en su caso, la que se describe, hallándose la misma integrada por varias agrupaciones aparceladas para poder proceder a su enajenación, según un plano levantado en la integra finca perteneciente al vendedor...". Frente a la acción negatoria dirigida en contra de los demandados para que la justicia declarara que no existía servidumbre alguna que gravara el predio del actor, y revocando la sentencia de la Audiencia Territorial de Palma de Mallorca, el TS consideró que "[e]l contenido literal de las inscripciones registrales que se acaban de transcribir viene a demostrar inequívocamente, la existencia de un signo aparente de servidumbre de paso, establecido por los propietarios únicos de la finca matriz, al abrir camino por el interior de la misma, con el decidido y expreso propósito de que sirvieran de acceso, comunicación y servicio a las distintas parcelas en que se pensaba fraccionar la total extensión del fundo, caminos que no fueron hechos desaparecer al tiempo de separarse o segregarse la propiedad de las distintas parcelas, sino precisamente todo lo contrario". TS, I I de noviembre de i988, Sala en lo Civil. Aranzadi RJ/I988/8435.

72 Guilarte, La constitución voluntaria de servidumbres, cit., 4I4 a 4I8; Cuadrado, Constitución de servidumbre por signo aparente, cit., IO6- I I 4; CUADRAdo PÉREz, La servidumbre de propietario, cit., i62-i 70; Díaz, Servidumbres, serventías y relaciones de vecindad, cit., 56, I I 3 y 246; Rebolledo, Tratado de servidumbres, cit., t. I, I06 y I07, en especial nota 2 I; Tur, Mediante signo aparente, cit., 592-598; Gallego Vera, J.Á., "Las servidumbres y el registro de propiedad", en Cerdeira Bravo de Mancilla, G. (ed.), Tratado de servidumbres, Madrid, La Ley, 20 I 5, 92 I-923. 
Es decir, las servidumbres formalmente estarían constituidas pero bajo la condición de que tenga lugar la enajenación de uno de los predios o al menos de una parte del fundo que adquiriría la calidad de dominante o sirviente 73 .

De manera que las críticas y argumentos señalados no han sido desinteresados, pues han pretendido el rechazo de la destinación formal del propietario en vistas de una construcción dogmática que permita lograr una modificación legal que introduzca la "servidumbre de propietario"; o bien, al menos logre la aceptación de una interpretación alternativa de las disposiciones legales tanto o más discutible que la referida al artículo 54I c.c. esp.

\section{El principio nemini res sua servit iure servitutis en beneficio del propietario y la reconducción del establecimiento formal de servicios efectuado por el propietario hacia la destinación del padre de familia}

A la luz de lo expresado en los acápites precedentes, se advierte que el principio nemini res sua servit iure servitutis se convirtió en una limitación jurídica relevante para los propietarios, generándole una serie de dificultades prácticas con consecuencias económicas. Las alternativas que permiten su solución se reducen en definitiva a dos: o se modifica la ley, introduciendo una excepción al principio vía admisión de la institución de la servidumbre de propietario, o bien se interpretan las disposiciones legales vigentes en materia de servidumbres a fin de dar sustento jurídico a las actuaciones formales unilaterales de los propietarios sobre sus predios que comporten la aceptación de la constitución de las servidumbres deseadas frente a terceros.

Sin perjuicio de que mientras lo primero no ocurra en nuestros países, no queda más que trabajar en la segunda alternativa; pensamos que esta última es la vía dogmática más adecuada para superar las dificultades a que se pretende hacer frente. En este sentido, no somos partidarios de la "servidumbre de propietario", pues no resulta razonable que la solución jurídica moderna pase por convertir al propietario en titular de derechos reales distintos al dominio. Es un verdadero contrasentido que al detentador del mayor señorío sobre una cosa se le deba auxiliar con otros derechos reales (en este caso de servidumbre), que le otorgan facultades ya contenidas en su mismo dominio junto al de la disposición jurídica, para lograr que su posición e interés prevalezca por sobre el interés y posición de terceros respecto de la cosa de que es dueño. Jurídicamente es un absurdo ${ }^{74}$.

73 Como ocurre con Cuadrado, que luego de las críticas argumenta en favor de la constitución condicional y concluye que esta es la solución que se debe acoger; ver CuAdrado, La servidumbre de propietario, I 98 ss. y 2 I 4 . En el mismo sentido, Díaz, Servidumbres, serventías y relaciones de vecindad, cit., 56 у 57; Reвolledo, Tratado de servidumbres, cit., t. I, 54 .

74 Expresamente en este sentido, Biondi, Las servidumbres, cit., n. ${ }^{\circ}$ 48, 2 I 3. 
La verdad es que las dificultades para el propietario han surgido curiosamente y en definitiva por la inadecuada comprensión o aplicación del propio principio nemini res sua servit iure servitutis. En efecto, este principio debe entenderse como un beneficio para el propietario y no como una limitación que eventualmente le puede causar perjuicios. Es un beneficio pues reconoce de un modo claro y absoluto que los propietarios no requieren ser titulares de derechos reales adicionales al dominio para usar, gozar y disponer del objeto de este dentro del marco constitucional-legal correspondiente, pues les basta la propiedad para obtener las ventajas que pudieran pretender de los respectivos predios. $Y$ no necesitan de otros derechos reales pues estos sólo pueden otorgar al propietario facultades parciales ya contenidas en el dominio, y por tanto poderes respeto a las cuales ya es consecuencialmente titular ${ }^{75}$. En otras palabras, el principio nemini res sua servit iure servitutis puede literalmente traducirse como "la cosa propia no sirve a ninguno por derecho de servidumbre", pero jurídicamente deben entenderse como que "ningún propietario necesita de un derecho de servidumbre para servirse de la cosa propia". Es este último el sentido que debe dársele de acuerdo a los fundamentos del principio vistos en el acápite I.

Lo anterior es de la máxima relevancia, pues es el cómo se le entienda lo que le da la naturaleza de beneficio o bien de limitación. No es igual decir que no necesita de servidumbres porque es dueño que decir que no puede constituir servidumbres porque es dueño. Lo primero da cuenta de la amplitud del dominio como el mayor poder o señorío sobre una cosa en que efectivamente consiste aquel, mientras que lo segundo da cuenta más bien de una restricción a que resulta sujeta la propiedad, que no es real.

Por lo mismo, no pueden prohibírsele o impedírsele al propietario actuaciones suyas que lo favorecen, fundando la prohibición o impedimento en el citado principio, pues implicaría el efecto inverso, como es causarle detrimento al dueño. Las interpretaciones del principio normalmente efectuadas y sus consecuencias han terminado precisamente por causarle perjuicios al dueño, configurando una indebida restricción a la propiedad, en circunstancias que debieran reflejar la amplitud del poder del propietario. Este absurdo al que ha sido llevado el nemini res sua servit iure servitutis ha terminado en la aparición de las excepciones legales vistas en el acápite II. El desarrollo de las llamadas "servidumbres de propietario" ha sido una manera de reconocer que si el propietario quiere servidumbres, y porque son de su interés (de ordinario patrimonial), debe permitírsele su constitución (como si estuviera prohibido), aunque aparentemente no las necesite para la satisfacción de dicho interés. La decisión es del propietario, y las legislaciones, con la introducción de las excepciones, procurarían su respeto, garantizando su oponibilidad frente a terceros.

75 Explica en términos simples la cuestión CuAdrado, La servidumbre de propietario, cit., 82 ss. 
La cuestión esencial no radica en buscar la forma de lograr la intervención del legislador para superar los efectos del principio nemini res sua servit iure servitutis. El punto es interpretar correctamente el principio, para luego poder interpretar a su vez, a la luz del verdadero sentido y alcance del mismo, las disposiciones legales relativas a servidumbres; o dicho de otra forma, para poder aplicar el principio correctamente en la interpretación de las normas del código civil y de las leyes especiales relacionadas. Se advierte entonces que el problema jurídico aquí no es si se interpreta una disposición legal de una manera extensiva o restrictiva, como podrían sugerir las argumentaciones de la doctrina española aludidas en el acápite precedente. El problema es primero determinar qué beneficia al propietario, conforme al principio nemini res sua servit iure servitutis y, a continuación, aplicar la norma en el sentido que más convenga al dueño, lo que podría comportar que el intérprete deba efectuar una lectura extensiva o restrictiva de las normas legales. Es decir, la mayor o menor amplitud en el resultado da lo mismo; lo relevante es que con dicho resultado quede resguardado el interés del propietario.

Así las cosas, tenemos que si el propietario establece un servicio entre dos predios o dos partes de un mismo predio bajo su domino, y la conservación de dicho servicio luego de efectuar un acto de disposición sobre alguno de los fundos o partes le beneficia, ya sea porque le aumenta el valor del predio, le permite el acceso al crédito o, en caso de remate de uno de sus predios, le permite seguir gozando del servicio (salvo expresión de voluntad o acuerdo con terceros en contrario), debe aplicarse el nemini res sua servit iure servitutis precisamente en el sentido que le favorezca. Y le será favorable por ejemplo reconociéndole frente al interés de terceros la constitución de las servidumbres en virtud de un título anterior. Lo contrario es perjudicarlo.

En virtud de lo antes dicho, y como ya adelantáramos, creemos que la solución más bien pasa por la interpretación de las disposiciones del código civil actualmente vigentes, en vez de introducir modificaciones legales que alteran el sistema. En particular, somos partidarios de que la cuestión de la constitución y adquisición de servidumbres por actuación unilateral del propietario se reconduzca efectivamente hacia la institución de la DPF, ya regulada en el código civil (arts. 88 I c.c. chil. y 938 c.c. col.). Esta solución, de paso, permite descartar la pretensión de fundar la adquisición de servidumbres en una tradición que seguiría a un supuesto acuerdo entre el propietario de los dos predios y el adquirente de uno de ellos, que alguno ha sostenido como posible alternativa ${ }^{76}$.

76 La sola referencia en la escritura pública de la compraventa a que "se adquiere con todos sus usos y servidumbres" sería suficiente prueba del acuerdo de voluntades (acto jurídico bilateral), el cual serviría de título a la tradición. En el sentido expuesto, Montory Barriga, G., "Las servidumbres recíprocas en loteos y parcelaciones", en Domínguez, C. et al. (eds.), Estudios de Derecho Civil VIII, Santiago, Legal Publishing Thomson Reuters, 2013, I22. La opinión predominante en doctrina es que la cláusula de estilo citada que se incorpora en las compraventas no 
La DPF es la expresión natural del principio nemini res sua servit iure servitutis, la cual permite articular el estadio de pleno ejercicio del derecho de dominio, impidiendo que para este fin se le exija al propietario la constitución de derechos ya contenidos en su propiedad, con el estadio de pérdida total de facultades (el dominio) o parcial (constitución de derechos en favor de terceros) sobre los predios entre los cuales estableció el servicio. Es la DPF la institución que precisamente cautela lo obrado por el dueño en situación de propiedad, y su tránsito hacia la situación de pérdida o limitación de esta respecto de uno o ambos predios.

En tal contexto, lo que corresponde es interpretar el requisito del "servicio aparente" de los artículos 88 I c.c. chil. y 938 c.c. col. en sentido amplio, comprendiendo dicha expresión tanto los signos externos materiales como los signos externos formales. De esta manera, las declaraciones voluntarias unilaterales formales con publicidad, inscritas en el registro inmobiliario, deben considerarse signos externos que dan cuenta de la existencia del establecimiento de un servicio por el propietario entre predios sujetos a su dominio. La señal no está materialmente en el predio, pero sí en relación al predio y dentro de los antecedentes públicos acerca del mismo a disposición de cualquier tercero.

Lo anterior resulta acorde a la realidad que modernamente tiene lugar en materia de adquisición de inmuebles, pues hoy en día no siempre el adquirente concurre al lugar en que se encuentra el bien raíz, tomando un conocimiento directo y personal de él. Más bien el adquirente toma conocimiento de la situación jurídica del bien raíz por sí o por intermedio de abogados o profesionales entendidos, a través del registro público de la propiedad así como también por medio de los diferentes registros públicos que llevan órganos administrativos sobre distintas cuestiones atingentes a ellos. La adquisición se fundamenta en razones económicas y en los estudios o informes correspondientes elaborados por los profesionales contratados al efecto. Por lo mismo, y en definitiva, la medida de publicidad para el conocimiento y oponibilidad a terceros del servicio concurre perfectamente.

La admisión de una interpretación amplia de "servicio aparente" permite dar una solución jurídica coherente con el paso de un estadio de dominio único de dos predios entre cuales el propietario establece un servicio, al estadio posterior en que la propiedad se encuentra separada, todo ello sobre la base del principio nemini res sua servit iure servitutis adecuadamente interpretado. Es decir, la propuesta está estrictamente relacionada con un requisito esencial en materia de servidumbres, como es la propiedad diferenciada de los predios. Por el contrario, lo que en el caso no tiene lugar; por otra, porque dicha cláusula señala genéricamente que se adquiere con todas las servidumbres que gravan el predio, en circunstancias que hasta el momento de la compraventa no existirían servidumbres constituidas. $V$. gr., Rebolledo, Tratado de servidumbres, cit., t. I, I 88 y I 89; Spanò y Caruso, Le servitù prediali, cit., 485 . 
no dice relación con otros requisitos que deberán concurrir, como es eventualmente la existencia misma de los dos predios.

En virtud de lo anterior, no debe confundirse la destinación formal del padre de familia con las llamadas "servidumbres para ventaja futura", novedad introducida en su momento por el artículo ro29 c.c. ital. de $1942^{[77]}$. Ciertamente, la DPF formal tiene especial relevancia para los casos de desarrollo de urbanizaciones, loteos o proyectos inmobiliarios en general, pues permite dar solución en buena parte a los problemas que se han tratado de superar mediante las servidumbres de propietario. Sin embargo, no son las únicas situaciones en que la DPF tendrá aplicación.

En efecto, el propietario de un predio puede establecer formalmente servidumbres entre los futuros lotes en que el fundo se subdividirá; o bien entre el predio común y los departamentos o unidades que se construirán en el predio; o entre estos departamentos y unidades, procediendo a inscribir dichas servidumbres en el registro inmobiliario. En estas situaciones, antes de que se divida el dominio, será necesario que "existan" los lotes o bien se construyan los departamentos o unidades respectivamente ${ }^{7}$. Pero perfectamente podría ocurrir, y de hecho sucede, que el propietario de dos o más lotes, o bien de un predio y de departamentos o de unidades, una vez que ya existen, y antes de su enajenación, establezca servidumbres entre ellos y las inscriba en el registro inmobiliario. En ambos casos, y según lo explicado en precedencia, las servidumbres nacerán por DPF al momento de la enajenación del lote, departamento o unidad correspondiente. Es evidente entonces que, exista o no uno o más de los predios entre los cuales se establece el servicio por el propietario único, la DPF sólo operará en la medida en que concurran todos los demás requisitos para que pueda nacer la servidumbre conforme a la ley.

En todo caso, las "servidumbres para ventaja futura" no hacen más que ratificar todo lo dicho en este trabajo. Ello debido a que si bien el artículo ro29 inciso $2 .^{\circ}$ c.c. ital. permite el establecimiento de servidumbres que favorezcan o graven un edificio por construir (futuro), y dispone que la constitución de la servidumbre solo tendrá lugar cuando el edificio sea construido, en parte alguna admite que la servidumbre sea establecida unilateralmente por el dueño del predio sobre el cual se construirá el edificio. En este sentido, la doctrina italiana mantiene la necesidad de que la servidumbre, aunque sea para una ventaja futura,

77 Expresamente alude a ellas Velásquez, Bienes, cit., 4I I y 4I 2, nota 4. Aunque tampoco deben identificarse en estricto rigor las servidumbres para ventaja futura con las servidumbres sobre edificio futuro. Ver Perlingieri, P., Rapporto preliminare e servitù su "edificio da costruire", Napoli, Jovene, I966, 29 ss.

78 Es más, histórico y aceptado como caso de la DPF es aquel del propietario de un predio que establece un servicio entre dos partes de él ( $\mathrm{y}$ al que hemos aludido en distintas partes del trabajo). Materialmente hay dos pedazos de tierra, pero jurídicamente no hay dos predios. Desde la aparición de los registros inmobiliarios se requiere de dos inscripciones distintas; y con el desarrollo del derecho urbanístico, hoy se exige previo a la inscripción una resolución administrativa que autorice la subdivisión. 
sea establecida mediante una "convención"79. ¿Y si el servicio fue efectivamente establecido unilateralmente respecto de un edificio por construir por el dueño del predio? Spanò y Caruso, dándose cuenta de las restricciones de la situación, señalan que se puede constituir una servidumbre para ventaja futura por $\mathrm{DPF}^{80}$, solo en el caso de enajenación de un edificio por construirse. Si bien ninguna servidumbre podría nacer mientras el edificio no se construya, y a pesar del apego a la DPF material que existe en Italia en virtud de los términos del artículo I06 I, los citados autores logran advertir la dirección correcta que debe asumir la interpretación si no quiere perjudicarse al propietario.

En síntesis, no le es posible al propietario constituir servidumbres entre predios de su propiedad o entre partes del predio que le pertenece a través de un acto jurídico unilateral, en virtud del principio nemini res sua servit iure servitutis, de acuerdo a lo explicado en el acápite I. Sin embargo, siendo de su interés, el propietario, en razón del mismo dominio, puede establecer servicios entre los predios respectivos o partes del predio si es uno solo. Este establecimiento puede ser realizado mediante una declaración formal unilateral de voluntad del propietario, pudiendo este, en razón de la formalidad del acto, solicitar que sea incorporado en el registro inmobiliario. Este convertirá sin dudas al servicio en "aparente" ${ }^{8}$, de modo que cuando tenga lugar la primera enajenación de uno de los predios o parte de un predio sobre el cual fue establecido el servicio, y por el solo ministerio de la ley, deberá entenderse constituida la servidumbre respectiva, si nada se expresa en contrario.

La ventaja de una destinación formal frente a una material será la posibilidad de establecer servicios negativos o materialmente inaparentes, los que se encontraban tradicionalmente excluidos de la DPF. La inapariencia material es reemplazada ahora por una apariencia jurídica registral.

\section{Argumentos complementarios en favor de la reconducción propuesta}

Sin perjuicio de que fundamentalmente la reconducción propuesta se logra y comprende a partir de la correcta aplicación del principio nemini res sua servit iure servitutis, existen algunas razones adicionales que refuerzan la misma, y que se pasan a revisar a continuación.

79 Branca, Servitù prediali, cit., 5 I; Spanò y Caruso, Le servitù prediali, cit., i4o. Por ejemplo, mediante convención, podrían acordar los dueños de dos predios vecinos la constitución de una servidumbre eléctrica o de paso sobre uno de ellos en favor de los departamentos que se construirán en el otro.

80 Spanò y Caruso, Le servitù prediali, cit., I42 .

8 I Ello es evidente, pero además, los mismos autores contrarios a la interpretación aquí sostenida, reconocen que una inscripción registral también es un signo aparente. $V$.gr., Tur, Mediante signo aparente, cit., 594 . 


\section{A. Históricamente la destinación del padre de familia fue formal}

La DPF fue reconocida con carácter formal en el derecho anterior al código civil francés. El artículo 2 I 6 de las “Costumbres de París” de I 580 modificó el texto del año I 5 Io de las mismas, estableciendo no sólo que la "destination de père de famille vaut titre", sino que ello tenía lugar "quand elle est ou a esté par escrit \& non autrement". Esta exigencia de que la DFP constara por escrito llevó a un gran debate doctrinario en Francia antes del proceso codificatorio, el que culminó con la opinión mayoritaria de que bastaba una destinación material. Esta fue precisamente la idea recogida en el Code.

Pero, ¿qué significa que baste la destinación material? Significa que la destinación material aparente y permanente es sólo el mínimo requerido para que opere este modo de constituir servidumbres; o sea, al menos deben existir signos externos materiales de la destinación efectuada por el propietario. Luego, en ningún caso se excluyen niveles mayores de seguridad de la destinación realizada, como sería por escrito (y menos una destinación que conste en un registro inmobiliario). De hecho, no fue la intención del legislador francés excluir las destinaciones formales, sino simplemente que no se exigiera que el destino conste por escrito $^{82}$. Por el contrario, las alternativas para el codificador francés eran exigir solo una destinación formal escrita constitutiva de escrituración (descartando la material), o bien extender el modo incluso a las destinaciones materiales. Elegir la primera posibilidad comportaba un modo constitutivo de servidumbres más restringido; la segunda un modo constitutivo de servidumbres más amplio. El codificador galo eligió la segunda, de manera que no puede ahora decirse que incluir como signo externo a las inscripciones en los registros inmobiliarios sería ampliar el sentido de la disposición más allá de lo querido por la ley, cuando fue el mismo legislador francés, y luego los que siguieron a este, quien introdujp la más amplia DPF posible.

Es más, una de las características que suele destacarse de este modo constitutivo de servidumbres es que no precisa de inscripción en el registro inmobiliario para que pueda exigirse su respeto por parte del propietario del predio dominante o por los terceros interesados ${ }^{8}$. Sin embargo, que no sea necesaria su inscripción no significa que no pueda esta realizarse, ni que este acto de publicidad no produzca los respectivos efectos.

\section{B. La destinación formal no está prohibida}

Con independencia de las noticias históricas, que en Francia y en el resto de los países herederos de su código de I804 se haya establecido que basta la destina-

82 Fenet, A., Recueil complet des travaux préparatoires du Code Civil, Paris, Au Dépot, I827, t. XI, 327.

83 Bonet, La constitución, cit., I39. 
ción fáctica no significa, aunque el código civil no lo diga expresamente, que no puede tratarse de una destinación voluntaria formal; o sea, la admisión de la menos exigente no comporta la prohibición de la más exigente, muy por el contrario. En la materia no cabe más que aplicar el viejo adagio qui potest plus, potest minus.

Habrá que recordar en este punto que el fundamento tradicional de la DPF fue la voluntad presunta del propietario y del adquirente de uno de sus predios en cuanto a coincidir en el deseo de constituir la servidumbre correspondiente, al no expresar voluntad contraria en el acto adquisitivo (de ahí que los códigos civiles regulen la figura en materia de servidumbres voluntarias $)^{84}$. Por ello la DPF es también designada como constitución tácita de servidumbres. Luego, si en vez de proceder el propietario a realizar solo una destinación de hecho, declara expresa y formalmente que establece un servicio, dicha declaración debe ser reconocida con mayor razón por el ordenamiento jurídico y entenderse constituida la servidumbre luego de la enajenación posterior. No puede resultar más absurda la conclusión contraria: ¡admitir la constitución tácita y rechazar la constitución expresa! No podemos estar de acuerdo con este absurdo, el cual quizás sería único en el derecho.

A mayor abundamiento, y continuando con el absurdo, de no admitirse como DPF las destinaciones formales, habría que aconsejar a los propietarios que en vez de declarar explícita y formalmente su voluntad, realicen destinaciones materiales, porque las destinaciones formales, más claras y más seguras especialmente para los terceros, no tendrían ningún valor; mientras que las materiales, menos claras y menos seguras para los terceros, sí que tendrían valor.

Llegar a estas tristes conclusiones, por simple tozudez o por apego a una superada interpretación exegética y restrictiva de los artículos 88 I c.c. chil. y 938 c.c. col., nos parece inaceptable.

\section{Interpretación acorde con la creación de los registros inmobiliarios}

Lo que fundamentalmente ha dado lugar al desarrollo de la idea de que es posible constituir servidumbres sobre cosa propia ha sido la creación de los registros de bienes raíces, inexistentes cuando se creó la DPF como institución y desconocidos particularmente por el $\operatorname{Code}^{85}$. En este sentido, es el propio Huber el que, desarrollando la doctrina de las servidumbres sobre cosa propia, trata

84 Así, p. ej., Pardessus, Trattato delle servitù, cit., n. ${ }^{\circ}$ 230, I 53. En Chile, la idea de la destinación entendida como voluntad presunta fue recogida por los primeros comentaristas al código y la doctrina tradicional que le siguió: Chacón, Estudio comparativo, cit., 577; VARAs, De las servidumbres, cit., 394; Claro Solar, Explicaciones, cit., vol. iv, t. 9. ${ }^{\circ}$, n. ${ }^{\circ}$ I640, 288.

85 Se recuerda que este código introdujo como regla que los contratos producen efectos reales. No existiendo entonces la distinción entre título y modo, no se contempló tradición alguna mediante inscripción. Solo la inseguridad llevó a la creación de un sistema registral de trans- 
expresamente la "destination du père de famille"86, reconociendo primeramente que esta era la vía natural para constituir servidumbres a partir de una decisión del propietario. La existencia y contenido de las servidumbres en predio propio solo se habrían logrado mediante estas destinaciones externas, sin perjuicio del establecimiento mediante contratos.

Huber entonces afirmaría que sin la ayuda de los registros formales inmobiliarios, las servidumbres sobre cosa propia se habrían mantenido en la misma situación, no alcanzando jamás un gran desarrollo. Son las formalidades del registro de bienes raíces las que habrían generado las condiciones legales requeridas para la necesaria confianza y certeza de propietarios y terceros ${ }^{87}$.

De manera que hay que considerar las nuevas circunstancias. No es posible seguir interpretando las disposiciones sobre DPF a la luz del contexto jurídico y social del siglo xix. Una línea interpretativa como esta sería lo mismo que seguir interpretando "carruaje" en sentido estricto ${ }^{88}$ y no entender el concepto referido a medios de transporte moderno (v. gr., automóvil). Una disposición como la del artículo 88 I c.c. chil. (938 c.c. col.), nacida para una época sin registros de propiedad, debe actualizarse y adecuarse a la existencia de registros de propiedad. Incluso más, la doctrina española que defiende la constitución de servidumbres bajo condición suspensiva precisamente, para llegar a esta conclusión, defiende una interpretación actualizada de las disposiciones del código civil. Esto último contrasta con la interpretación del artículo 54 I c.c. esp., respecto al cual, como hemos dicho, la mayoría plantea una interpretación restrictiva y clásica. La inconsecuencia de la doctrina española en este sentido es patente: para la constitución de servidumbres por acto jurídico unilateral sujetas a condición, que es un invento doctrinario, la interpretación debe ser moderna y amplia. Para interpretar los "signos aparentes", la interpretación debe ser histórica y restrictiva. La lectura según la conveniencia del resultado es evidente, no pudiendo sino rechazarse ${ }^{89}$.

cripción por ley de i855. Ver sobre este Caicedo Escobar, E., Derecho inmobiliario registral, Bogotá, Temis, $200 \mathrm{I}^{2}, 74$ ss.

86 Huber, Die eigentümerdienstbarkeit, cit., 55 ss.

87 Huber, Die eigentümerdienstbarkeit, cit., 68.

88 El término "carruaje" aún se encuentra en los artículos 574, I I 22 y 20 I 5 c.c. chil. (662, i I 80 y 2072 c.c. col.).

89 Así Cuadrado, quien por una parte se opone a la aplicación analógica del artículo 54 I c.c. esp. por considerar que no existe la misma "identidad de razón" para efectuar la extensión y ser una disposición de carácter excepcional, pero por otra alega la indispensable adecuación de las leyes a las circunstancias de cada época, y acude a elementos sociológicos y teleológicos para defender la interpretación que pretende. CuADrado, La servidumbre de propietario, cit., I 57 a I 59 y 166 a 198 . 


\section{Consagración legal de la solución en algunos países}

Los artículos 72 I inciso 2. ${ }^{\circ}$ c.c. ven., I I 83 del Estado de Quebec y 564 del Código Foral de Aragón ${ }^{\circ}$ regulan en realidad expresamente la destinación formal del padre de familia y no la institución de la servidumbre de "propietario".

Lo interesante de esta fórmula es que si bien los legisladores pudieron pretender la introducción de servidumbres sobre cosa propia, en definitiva respetaron el principio nemini res sua servit iure servitutis, reconduciendo explícitamente la nueva regulación hacia el modo de adquirir tradicional de servidumbres denominado DPF. Lo lograron simplemente con la aceptación expresa de las destinaciones formales. No se introdujeron por tanto instituciones nuevas, disonantes con el sistema, sino una solución dentro de este.

El caso más claro es el venezolano, pues regula en la misma disposición la DPF por destinación material y por destinación formal. Al respecto, es interesante señalar que la doctrina venezolana ha particularmente destacado que la constitución mediante escritura protocolizada en la Oficina Subalterna de Registro, conforme reza el artículo 72 I c.c. ven., es aplicable a cualquier especie de servidumbre, es decir, incluso a las inaparentes por la falta de signos externos materiales ${ }^{\mathrm{I}}$.

El Código Aragonés, por su parte, distingue entre constitución por signo aparente (art. 566), que sería la tradicional DPF, y constitución de "servidumbre de propietario" (art. 564), por medio de escritura pública e inscripción registral92. Sin embargo, el tenor del artículo 564, la motivación de la nueva reglamentación del código aragonés 93 y la doctrina respectiva 94 dejan en claro que en definitiva la segunda institución no es sino la misma DPF pero formal, pues la servidumbre solo produce efectos cuando hay enajenación de uno de los predios. De hecho, Bellod trata de establecer la diferencia entre la antigua DPF y la nueva

90 Ver notas 40, 44 y 45 .

9I Kummerow, Gert, Bienes y derechos reales, Derecho civil II, Caracas, Universidad Central de Venezuela, I969², 505; Оснон G., Ó., Bienes y derechos reales, Caracas, Universidad Católica Andrés Bello, 2008, 437 y 438; Aguilar Gorrondona, J. L., Cosas, bienes y derechos reales, Caracas, Universidad Católica Andrés Bello, 20099, 444 y 445.

92 Alonso Pérez, M. T., “Constitución y extinción de las servidumbres”, en Bayod, C. (ed.), Derecho civil patrimonial aragonés, Zaragoza, Institución 'Fernando El Católico' (c.s.I.c.), 2013 , 159 y I60.

93 Las palabras del preámbulo del código aragonés expresan sintéticamente la doctrina que hemos sostenido: "criterio innovador establece el artículo 564 al admitir la constitución de servidumbre sobre finca propia, atendiendo a requerimientos de la práctica. Naturalmente, mientras ambas fincas pertenezcan a un único propietario, éste ejercerá todas sus facultades iure proprietatis, pero el Registro de la Propiedad podrá publicar la constitución de la servidumbre, que tendrá toda su eficacia cuando alguna de las fincas cambie de titular".

94 Reconoce que con base en el artículo ${ }_{5}^{6} 4$ las servidumbres prediales no pueden ser eficaces cuando la propiedad pertenece al mismo sujeto, Alonso, Constitución y extinción de las servidumbres, cit., I59 y i6o; Bellod Fernández de Palencia, E., "Servidumbres: concepto, clases, caracteres, contenido de las servidumbres", en BAYOD, Derecho civil patrimonial aragonés, cit., I39. 
figura del artículo 564 , pero en su intento no hace más que poner a la vista que se trata esta última sólo de una DPF formal. Afirma la autora que podría alegarse que el supuesto que se comenta ya se solucionaba en la práctica, "y es cierto, pero aplicando por analogía el artículo 54I del Código Civil que tiene su homólogo en el artículo 566 de código aragonés". Se aplicaba en su concepto el artículo 54I c.c. esp. de manera un tanto forzada, intentando darle un cauce legal a un supuesto que no lo tenía (aparentemente, diríamos nosotros) a través de un precepto que no respondía a esa finalidad 95 . En otras palabras, para que nadie tenga dudas acerca de la admisibilidad de la DPF formal, ya que el precepto legal que la regula nada decía, la ley ahora la recoge expresamente. Pero a la vez, reconoce que cuando no regía aún la nueva disposición, la cuestión debía reconducirse a través de la tradicional DPF.

Finalmente, el solo tenor del artículo i 83 de Quebec pareciera dar a entender que estamos en presencia de una servidumbre de propietario. Mas, la definición de servidumbre del artículo i 77 mantiene la necesidad de la ajenidad de los fundos y el artículo i i9 I dispone la extinción de las servidumbres por la reunión de la propiedad en manos de un mismo propietario. Luego, el efecto del artículo I 83 no puede ser el nacimiento inmediato de la servidumbre, sino una destinación formal que solo adquiere el carácter de servidumbre al momento de la separación de los predios. Es lo que han expresado los tribunales de justicia ${ }^{9}$, ratificando este sentido de la disposición la propia doctrina canadiense, que estima consagrada en ella la "destination du propriétaire" 97 . La forma escrita es considerada un medio de prueba, que permitirá además la inscripción de la destinación en el registro inmobiliario precisamente para que resulte oponible a terceros ${ }^{9}$.

\section{E. Coherencia sistémica con la legislación especial en el caso de Chile}

En Chile, la legislación especial acepta la destinación formal del padre de familia en las denominadas "servidumbres de alcantarillado" en predios urbanos reguladas por Ley 6977 de I94I. La hipótesis regulada por su artículo 2..$^{\circ}$ es sustancial y evidentemente la misma que la del artículo 88 I c.c. chil.99. En este sentido, la

95 Bellod, Servidumbres, cit., I40.

96 La constitución de la servidumbre por destinación del propietario se produce en dos etapas: en la primera, previendo la posible subdivisión de sus fundos, el dueño establece por escrito el lugar, la naturaleza y alcance de la servidumbre; pero sólo "À la seconde, au moment du morcellement, la servitude prend effet". CA, 23 de junio de 2015, Dossier 200-09-008 I I I-I 37, FERLAND $c$. TURGEON, 2015 QCCA I I I 3 (CanLII), disponible en: http://canlii.ca/t/girmk

97 Lafond, P.-C., Précis de droit de biens, Montréal, Thémis, 2007, n. ${ }^{\circ} 2024,889$.

98 Ver en obra anterior, n. $^{\circ} 2034,892$, y n. $^{\circ} 2044,898$.

99 Art. 2..$^{\circ}$ "Si el dueño de predio establece un servicio de alcantarillado en favor de otro predio que también le pertenece, deberá otorgar escritura pública en que conste la instalación e ins- 
doctrina ha reconocido que esta ley aplicó la DPF como forma constitutiva de las respectivas servidumbres ${ }^{\text {I0O }}$.

Antes de la existencia de la citada disposición legal, y dada la interpretación tradicional del artículo 88 I c.c. chil. (938 c.c. col.), se producían graves inconvenientes para el propietario que disponía de un servicio de alcantarillado de carácter subterráneo entre predios bajo su dominio. En caso de enajenación, y dada su ubicación en el subsuelo, no se entendía constituida la servidumbre por DPF, por no cumplir con el requisito material de la apariencia.

La dificultad se solucionó aplicando el legislador la institución de la DPF, aceptando expresamente la posibilidad de efectuar la destinación de manera formal (por escritura pública) y aceptando como signo exterior del servicio, esto es, como medio de publicidad, la inscripción en el Registro de hipotecas y gravámenes del Conservador de Bienes Raíces.

\section{Conclusiones}

De acuerdo a todo lo dicho en los acápites precedentes, podemos concluir sintéticamente lo que siguiente.

a. El propietario de uno o más predios, en virtud del principio nemini res sua servit iure servitutis, no necesita de servidumbres para disponer que uno de ellos sirva al otro u otros, o que una parte de un predio bajo su dominio sirva a otra parte del mismo predio.

b. El citado principio debe entenderse en beneficio del propietario y no como una limitación a su derecho de propiedad, debiendo interpretarse y aplicarse las disposiciones legales sobre servidumbres de manera que hagan efectivo dicho beneficio.

c. En tal contexto, el principio en cuestión no puede jamás impedir al propietario establecer servicios formalmente a través de una declaración unilateral de voluntad entre dos o más predios bajo su dominio o partes de un mismo predio, resultando además admisible la publicidad de dicho acto a través del registro inmobiliario correspondiente.

d. Si bien el acto jurídico unilateral del propietario no es suficiente para constituir el servicio establecido como servidumbre, dicha actuación y su posterior publicidad registral comportarán la existencia de un "servicio aparente" en términos de los artículos 88 i c.c. chil. y 938 c.c. col. Porque en esta expresión deben comprenderse no solo los servicios establecidos por el dueño que presenten

cribirla en el conservador.- Si el dueño enajena después uno de los predios, o pasan a ser de diversos dueños por partición u otra causa, subsistirá el mismo servicio entre ambos predios, a menos de estipularse otra cosa también por escritura pública inscrita".

Ioo Señala expresamente que la Ley 6977 contempla esta forma de constitución, PeÑallillo, Los bienes, cit., 507 . 
señales exteriores "materiales", sino también los servicios que presentan señales exteriores "jurídicas", como es el caso de la publicidad del acto en el registro inmobiliario.

e. Constituyendo la destinación formal del propietario un "servicio aparente" entre predios o entre partes de un predio que le pertenecen, y en virtud de las disposiciones legales citadas, dicho servicio adquiere el carácter de servidumbre cuando el titular del dominio enajene uno de los predios o una de las partes entre las cuales se estableció el servicio a un tercero, o bien se adjudiquen ellos a distintos herederos, sin que en el acto de enajenación o partición se establezca expresamente otra cosa. El mismo efecto, aunque los artículos antes señalados no lo indiquen expresamente, tendrá lugar cuando sean transmitidos los predios o partes de un predio a diferentes legatarios, o uno a un legatario y otro a uno o más herederos, pues se cumplirá en esta hipótesis igualmente con el requisito de la ajenidad de los predios entre los cuales el servicio fue establecido.

f. De esta manera, la solución de todos los problemas que se producirían para el propietario por el no nacimiento de la servidumbre al momento del otorgamiento del acto jurídico unilateral de destinación no pasa por introducir excepciones legales al principio nemini res sua servit iure servitutis ni por modificar el código civil para recoger la institución de la servidumbre de propietario o, en su defecto, expresamente la destinación del padre de familia formal. Basta con interpretar de un modo adecuado las disposiciones vigentes y admitir la razonabilidad de la destinación formal con publicidad, quedando esta comprendida en la clásica institución de la "destinación del padre de familia", que producirá efectos constitutivos por el solo ministerio de la ley al momento de la concurrencia del requisito de la ajenidad.

\section{Bibliografía}

Aguilar Gorrondona, J. L., Cosas, bienes y derechos reales, Caracas, Universidad Católica Andrés Bello, $2009^{9}$.

Arangio-Ruiz, V., "Note brevi sulla struttura dei diritti frazionarii", en Scritti di diritto romano IV, Napoli, Jovene, I977.

Arévalo Guerrero, I. H., Los bienes, Constitucionalización del derecho civil, Bogotá, Universidad Externado de Colombia, 20 I 2.

Arjona Guajardo-Fajardo, J. L., "El derecho de vuelo en nuestro ordenamiento (consideraciones a propósito de unas recientes resoluciones)", Revista Crítica de Derecho Inmobiliario, Madrid, 664, 200 I. 
Barcia Lehmann, Lecciones de derecho civil chileno. De los bienes, t. iv, Santiago, Jurídica de Chile, 2008.

Barcia Lehmann, R., Código Civil. Doctrina y jurisprudencia, t. I, Santiago, Thomson Reuters, 20 IO.

Bayod, C. (ed.), Derecho civil patrimonial aragonés, Zaragoza, Institución 'Fernando El Católico' (c.s.I.c.), 2013.

Beauvarlet, P., Les servitudes, Paris, Defrénois, 20 I 3.

Biondi, B., Las servidumbres, trad. José Manuel González Porras, de la 2. a ed., Granada, Comares, 2002.

BIondi, B., Le servitù prediali nel diritto romano, Milano, Giuffrè, I969².

Bonet Correa, J., La constitución de las servidumbres por signo aparente, Madrid, Consejo Superior de Investigaciones Científicas, I970.

Bonet Correa, José, "La interpretación jurisprudencial y doctrinal del artículo 54I del código civil en la década I987-1997”, Revista de Derecho Privado, Madrid, 2, I999.

Branca, G., "Servitù prediali", en Galgano (ed.), Commentario del Codice Civile Scialoja-Branca, Libro Terzo, Bologna y Roma, Zanichelli y Foro Italiano, I $987^{6}$, reimpr., Milano I999.

Burdese, A., Le servitù prediali, Linee teoriche e questioni pratiche, Padova, Cedam, 2007.

Butera, A., "Delle servitù stabilite per fatto dell'uomo", en Il diritto civile italiano, Delle servitù prediali, vol. 3, Torino, Utet, I923.

Caicedo Escobar, E., Derecho inmobiliario registral, Bogotá, Temis, 200 I $^{2}$.

Cerdeira Bravo de Mancilla, G. (ed.), Tratado de servidumbres, Madrid, La Ley, 2015 .

Chacón, J., Estudio comparativo del código civil chileno, t. II, Santiago, Imprenta Nacional, i $890^{3}$. 
Claro Solar, L. Explicaciones de derecho civil chileno y comparado, De los bienes, Santiago, Jurídica de Chile, 20 I 5.

Claro Solar, L., "La destinación del padre de familia como título de la servidumbre voluntaria”, Revista de Derecho y Zurisprudencia, Santiago, I9, I922.

Cuadrado Pérez, C., La servidumbre de propietario, Madrid, Colegio de Registradores de la Propiedad y Mercantiles de España, 2008.

Cuadrado Pérez, C., Constitución de servidumbre por signo aparente, Cuadernos de Derecho Registral, Madrid, 2007.

Dávila García, J. y Valverde Madrid, J., “Comentario a sentencia del TS de i 7 de diciembre de I954", Revista de Derecho Notarial, Madrid, 8, I955.

De Ibarrola, A., Cosas y sucesiones, México D. F., Porrúa, $2004^{\mathrm{I} 4}$.

De la Mata Pizaña, F. y Garzón Jiménez, R. Bienes y derechos reales, México D. F., Porrúa, 20I $4^{7}$.

Del Arco Torres, M. Á. y Pons González, M., Régimen jurídico de las servidumbres, Granadas, Comares, $2008^{5}$.

Díaz Fuentes, A., Servidumbres, serventías y relaciones de vecindad, Barcelona, Bosch, 2004.

Domat, J., Loix civiles dans leur ordre naturel, Paris, I 7 I 3.

Enneccerus, L.; Kipp T. y Wolff, M., Tratado de derecho civil, Derecho de cosas, trad. Blas Pérez y José Alguer, Barcelona, Bosch, I98I33.

Escriche, J., Diccionario razonado de legislación y jurisprudencia, Madrid, I $845^{2}$.

Fenet, A., Recueil complet des travaux préparatoires du Code Civil, Paris, Au Dépot, I 827 .

García Alguacil, M. J., Consolidación y derechos reales en cosa propia, Granada, Comares, 2002.

García, J. M., "Comentario a sentencia del TS de 2 I octubre i976", Revista Crítica de Derecho Inmobiliario, Madrid, 529, I978. 
Grosso, G., Le servitù prediali nel diritto romano, Torino, Giappichelli, I969.

Grosso, G. y Deiana, G., Le servitù prediali, t. I, Torino, Utet, I955².

Guilarte Gutiérrez, V., La constitución voluntaria de servidumbres en el derecho español, Madrid, Montecorvo, I984.

Hedemann, J. W., Derechos reales, trad. José Luis Diez Pastor y Manuel González Enríquez, Madrid, Revista de Derecho Privado, I955.

Heineccius, J.G., Elementa ivris romani, Compluti, i 808.

Huber, E., Die eigentümerdienstbarkeit, ein Beitrag zu ibrer Rechtfertigung, Bern, Stämpfli \& Cie, I902.

Huber, E., Los derechos reales en el derecho privado suizo. Los preceptos de forma en el derecho privado suizo, trad. Enrique Ramos, Madrid, Centro de Estudios Históricos, I9r9.

Jordano Fraga, F., "Prehorizontalidad y servidumbre de propietario", Revista de Derecho Notarial, Madrid, I I3-I I4, I98I.

Jorquera Carvajal, M., De las servidumbres (Título XI - Libro 2. ${ }^{\circ}$ C. Civil), tesis de grado para optar al título de licenciado, Universidad de Chile, Valparaíso, Imprenta Comercial, I937.

Kummerow, G., Bienes y derechos reales, Derecho civil II, Caracas, Universidad Central de Venezuela, I969².

Lafond, P.-C., Précis de droit de biens, Montréal, Thémis, 2007.

Llácer Matacás, M. R., El título constitutivo de servidumbre en el artículo 54 I del código civil, Barcelona, Bosch, I996.

Lecaros Sánchez, J. M., Las cauciones reales. Prenda e hipoteca, Santiago, Metropolitana, $2009^{2}$.

López DE Tovar, G., Los códigos españoles: concordados y anotados, M. Rivadeneyra (ed.), Madrid, Imprenta de la Publicidad, i 848.

Longo, C., "La categoria delle 'servitutes' nel diritto romano classico", BIDR, Roma, I I, I 898. 
Mateo Borge, I., La servidumbre de propietario, Madrid, Marcial Pons, 2000.

Montory Barriga, G., "Las servidumbres recíprocas en loteos y parcelaciones", en C. Domínguez et al. (eds.), Estudios de Derecho Civil VIII, Santiago, Legal Publishing Thomson Reuters, 2013.

Оснол G., Ó., Bienes y derechos reales, Caracas, Universidad Católica Andrés Bello, 2008.

Pardessus, J. M., Trattato delle servitù, trad. R. Mercurio, de la 2. ${ }^{\mathrm{a}}$ ed., Napoli, I 832 .

Peñailillo Arévalo, D., Los bienes, Santiago, Jurídica de Chile, 2006.

Perlingieri, P., Rapporto preliminare e servitù su "edificio da costruire", Napoli, Jovene, I966.

Rebolledo Varela, Á. L. (ed.), Tratado de servidumbres, Navarra, Aranzadi, $2013^{3}$.

Rogron, J. A., Code civil expliqué. Par ses motifs et par ses exemples, Bruxelles, Tarlier, $1829^{5}$.

Rojina Villegas, R., Compendio de derecho civil, México D. F., Porrúa, $2015^{45}$.

Rozas Vial, F., Los bienes, Santiago, Conosur, I 998.

Ruz LÁrtiga, G., Explicaciones de derecho civil, Santiago, Abeledo Perrot, 20 i I.

San Martín Devoto, D., Las servidumbres, Santiago, Conosur, I 998.

Somarriva Undurraga, M., Tratado de las cauciones, Santiago, Nascimiento, I 943.

Solazzi, S., Requisiti e modi di costituzione delle servitù prediali, Napoli, I947.

Solazzi, S., "Sul principio 'Nemini res sua servit", SDHI, Ciudad del Vaticano, I 8 , I952.

Spanò, G. y Caruso, S., Le servitù prediali, Milano, Giuffrè, 20 I 3.

Tamayo, A., El derecho real de servidumbre. Estudio de una revisión del Código Civil en materia de servidumbres, Barcelona, Bosch, I956. 
Tavolari, R. (ed.), Doctrinas esenciales, Derecho civil, Bienes, Revista de Derecho y Jurisprudencia, Edición Bicentenario, Santiago, Puntolex, 20 ı .

Ternera Barrios, F., Derechos reales, Bogotá, Temis, 20 I $5^{4}$.

Terré, F. y Simler, Ph. Droit civil: Les biens, Paris, Dalloz, 20 I499.

Varas Videla, E. De las servidumbres, tesis de grado para optar al título de licenciado, Universidad de Chile, Santiago, I925.

Velásquez Jaramillo, L. G., Bienes, Bogotá, Temis, $2014^{\mathrm{I} 3}$.

Venezian, G., Usufructo, uso y habitación, Madrid, Revista de Derecho Privado, I 928 .

Vodanovic Haklicka, A., Tratado de los derechos reales, versiones de clases escritas de los profesores Alessandri, A. y Somarriva, M., t. II, Santiago, Jurídicas de Santiago, $2016^{7}$. 